\title{
Measurements of Premixed Turbulent Combustion Regimes of High Reynolds Number Flames
}

\author{
Jacob E. Temme ${ }^{1}$, Timothy M. Wabel ${ }^{2}$, Aaron W. Skiba ${ }^{3}$, and James F. Driscoll ${ }^{4}$ \\ Department of Aerospace Engineering \\ University of Michigan, Ann Arbor MI 48109
}

\begin{abstract}
The goal of this research is to empirically identify the boundaries between different regimes of premixed turbulent combustion that appear on the diagrams of Borghi and Williams. To date, four conditions have been extensively studied. The most intense of the four conditions possesses a turbulence level $\left(u^{\prime} / S_{L}\right)$ of 185 , an integral length scale $\left(\lambda / \delta_{F, L}\right)$ of 46 , and a turbulent Reynolds number of 69,000 . At present, the data set is too limited to plot boundaries on the regime diagrams. However, the four conditions have been categorized into their appropriate regimes. The structure and the thicknesses of the reaction zones were determined from simultaneous PLIF images of formaldehyde $\left(\mathrm{CH}_{2} \mathrm{O}\right)$ and $\mathrm{OH}$. Locally distributed reactions and shredded (i.e. broken) flamelets were observed in these images. The burning fraction varied between 0.75 and 1.0, indicating that up to $25 \%$ of the reaction layer was locally extinguished where "holes" were formed. The reaction or preheat zones associated with a particular condition were classified as being "globally distributed" if the mean thickness for that condition exceeded four times the laminar value. If a particular reaction zone is both four times thicker than the laminar value and its length to thickness ratio is less than four it is identified as being "locally distributed." In contrast, if this ratio exceeds four or the zone is not locally four times thicker than the laminar value it is considered to be thickened. While none of the cases were identified as being "globally distributed;" some of the cases were "partially distributed;" this is defined to occur when more than $25 \%$ of the reaction surface consists of "locally distributed" reaction zones. The preheat zone thickness was deduced from the $\mathrm{CH}_{2} \mathrm{O}$ PLIF images. Three of the four conditions, in which the turbulent Reynolds number exceeded 20,000, were found to have "globally distributed" preheat zones. Thickening of the preheat zone is believed to be enhanced when "holes" allow hot products to rapidly mix with the reactants. Previous studies conducted at much lower turbulent Reynolds numbers rarely observed local extinction within the reaction layer.
\end{abstract}

\section{Introduction}

Recent years have seen considerable interest in the study of premixed turbulent combustion. Despite impressive progress in several areas of combustion science, a fundamental understanding of the physics underlying turbulent premixed flames remains elusive. Although many researchers ${ }^{1-10}$ have examined combustion at large

\footnotetext{
${ }^{1}$ Post-Doctoral Research Fellow, Department of Aerospace Engineering, AIAA Member.

${ }^{2}$ Research Assistant, Department of Aerospace Engineering, AIAA Member.

${ }^{3}$ Research Assistant, Department of Aerospace Engineering, AIAA Member.

${ }^{4}$ Professor, Department of Aerospace Engineering, AIAA Fellow.
} 
turbulence intensities $\left(u^{\prime} / S_{L}\right.$, where $u^{\prime}$ is the r.m.s. velocity fluctuation and $S_{L}$ is the unstretched laminar burning velocity), these studies only achieved small integral length scales, which were typically less than $3 \mathrm{~mm}$.

Unfortunately, most realistic combustion problems occur under conditions of both large turbulence intensity and large integral length scale $(\lambda)$. Therefore there is a gap between the current state of research and practical application. The present work aims to narrow this gap by exploring a combustion regime of both large turbulence intensity $\mathrm{u}^{\prime} / \mathrm{S}_{\mathrm{L}}$ and large length scale $\lambda / \delta_{\mathrm{F}, \mathrm{L}}$. The importance of the large $\mathrm{u}$ ' and $\lambda$ suggests the use of the turbulent Reynolds Number (with kinematic viscosity $v$ ),

$$
\operatorname{Re}_{\mathrm{T}}=\mathrm{u}^{\prime} \lambda / v
$$

Another governing parameter of turbulent premixed combustion is the Damköhler number, which is the ratio of the flow time scale to the chemistry time scale (and thus approaches zero as the turbulence becomes dominant to the chemistry):

$$
\operatorname{Da}_{\mathrm{T}}=\left[\mathrm{S}_{\mathrm{L}}^{2} / v\right] /\left[\mathrm{u}^{\prime} / \lambda\right]
$$

Despite the importance of these parameters in highly turbulent premixed flames, the regime of large $\operatorname{Re}_{\mathrm{T}}$ and small $\mathrm{Da}_{\mathrm{T}}$ has remained relatively unexplored. For instance, prior to 2009 flame structure imaging experiments typically did not exceed a $\mathrm{Re}_{\mathrm{T}}$ of $2,000^{1-11}$. These previous experiments contained nearly continuous reaction surfaces. In 2009 Dunn et al. ${ }^{12,13}$ investigated premixed flames with $\mathrm{Re}_{\mathrm{T}}$ up to 5,500, where some local extinction of the flame was observed. More recently, Zhao et al. ${ }^{14}$ also reported flame structure in which $\mathrm{Re}_{\mathrm{T}}$ was approximately 5,000. However, no database exists for $\mathrm{Re}_{\mathrm{T}}$ above 5,500. On the other hand, Aspden et al. ${ }^{15}$ studied threedimensional Hydrogen flames in a box with direct numerical simulation, and observed the existence of distributed combustion when $\mathrm{Da}_{\mathrm{T}}$ was $1.52 \times 10^{-2}$. This illustrates the dual importance of $\mathrm{Re}_{\mathrm{T}}$ and $\mathrm{Da}_{\mathrm{T}}$ in any premixed turbulent combustion experiment.

There are currently two ways of plotting a regime diagram. The first is the regime diagram as proposed by F. Williams ${ }^{16}$, which plots $\mathrm{Da}_{\mathrm{T}}$ as a function of $\mathrm{Re}_{\mathrm{T}}$ on a $\log$-log scale (Figure 1a). The other method is that proposed by Borghi ${ }^{17}$ and Peters ${ }^{18}$, which adopts $\mathrm{u}^{\prime} / \mathrm{S}_{\mathrm{L}}$ and $\lambda / \delta_{\mathrm{F}, \mathrm{L}}$ as the governing parameters (this 'Borghi Diagram' is given in Figure 1b). Also included in the regime diagrams are the present experimental test cases. The present work achieves conditions of large $\mathrm{Re}_{\mathrm{T}}$ and small $\mathrm{Da}_{\mathrm{T}}$, where both the turbulence intensity and integral length scale are very large.

Note also that the $\mathrm{x}$-axis in the Borghi regime diagram is normalized by the unstretched laminar flame thickness, $\delta_{\mathrm{F}, \mathrm{L}}$. This value is defined as the summation of the unstretched laminar thicknesses of the reaction and preheat zones, respectively:

$$
\delta_{\mathrm{F}, \mathrm{L}}=\delta_{\mathrm{PH}, \mathrm{L}+} \delta_{\mathrm{RZ}, \mathrm{L}}
$$

In addition, the turbulent flame thickness will be the combination of the turbulent preheat and reaction zone thicknesses:

$$
\delta_{\mathrm{F}, \mathrm{T}}=\delta_{\mathrm{PH}, \mathrm{T}+} \delta_{\mathrm{RZ}, \mathrm{T}}
$$

The measurement of the quantities in Eq. (4) is one of the objectives of this work. 


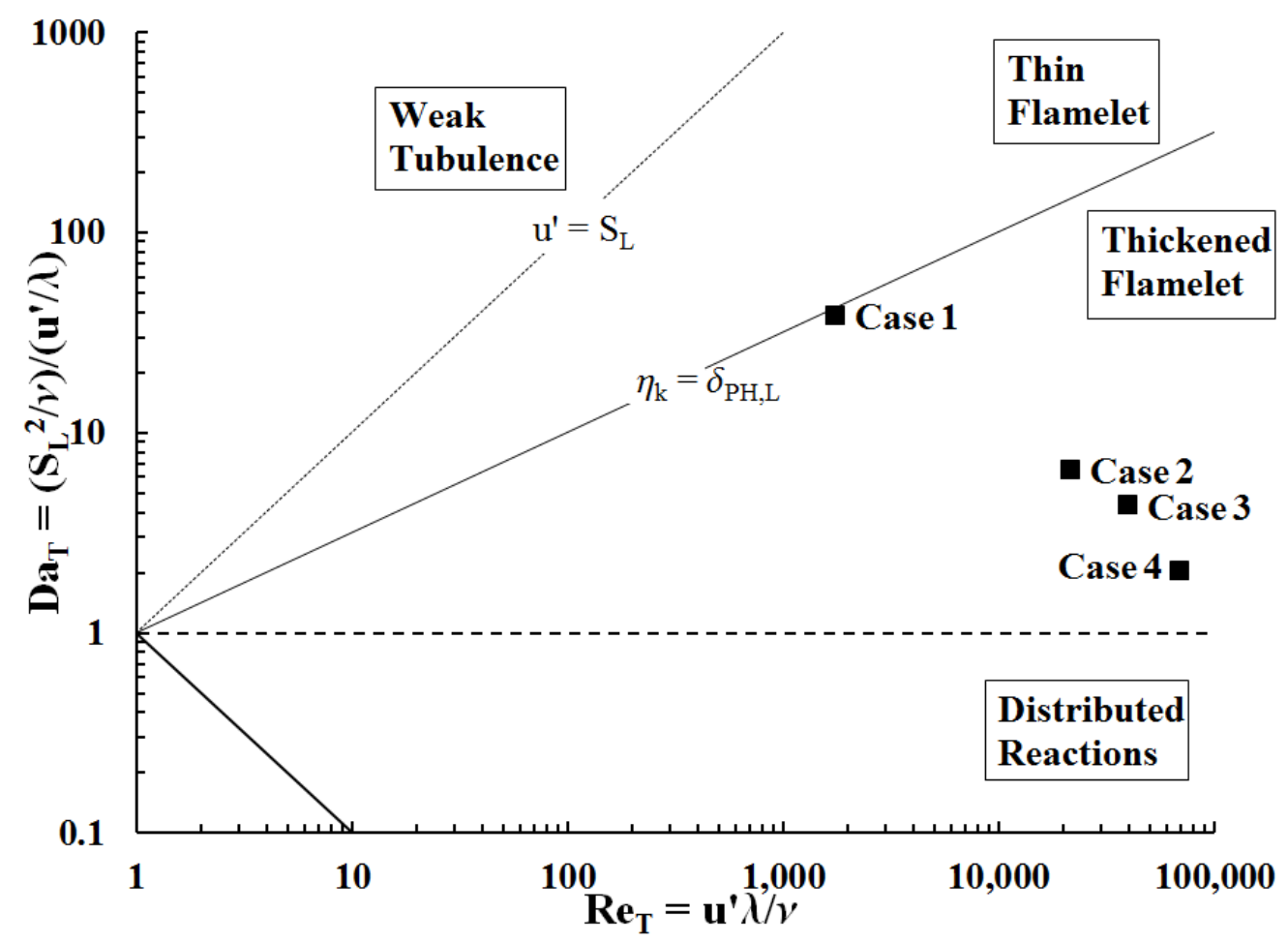

(a)

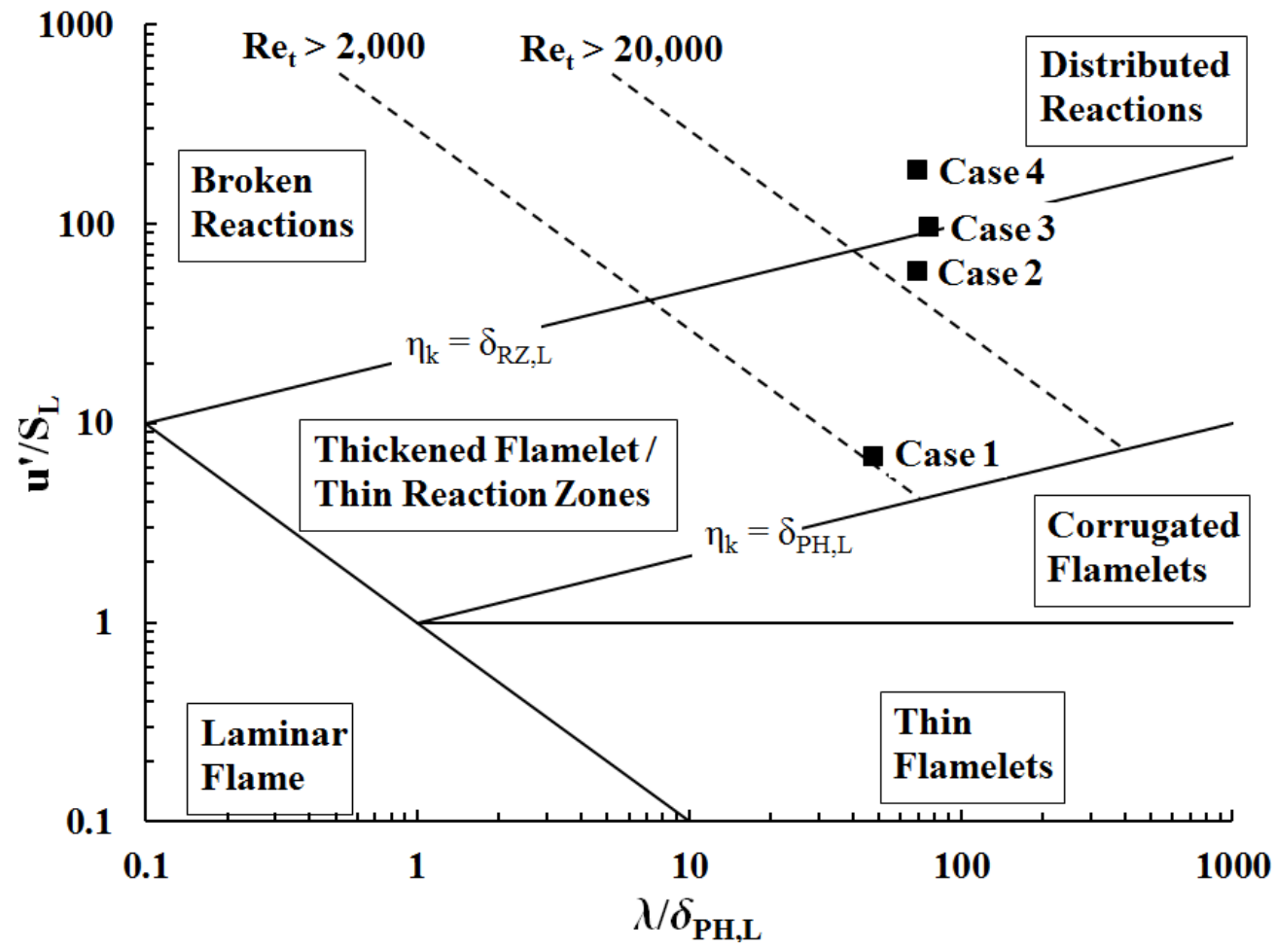

(b)

Figure 1. Regimes of Turbulent Premixed Combustion as proposed by F. Williams ${ }^{16}$ in (a) and by Borghi ${ }^{17}$, and Peters $^{18}$ in (b). 


\section{Experimental configuration}

This section outlies the experimental setup and the diagnostics used to conduct the work presented in this paper.

\section{A. Burner design and diagnostics}

The Hi-Pilot Burner is illustrated below in Figure 2.

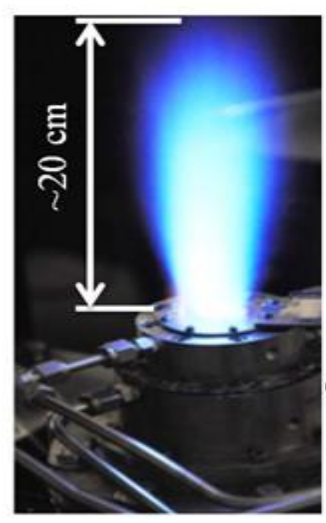

(a)

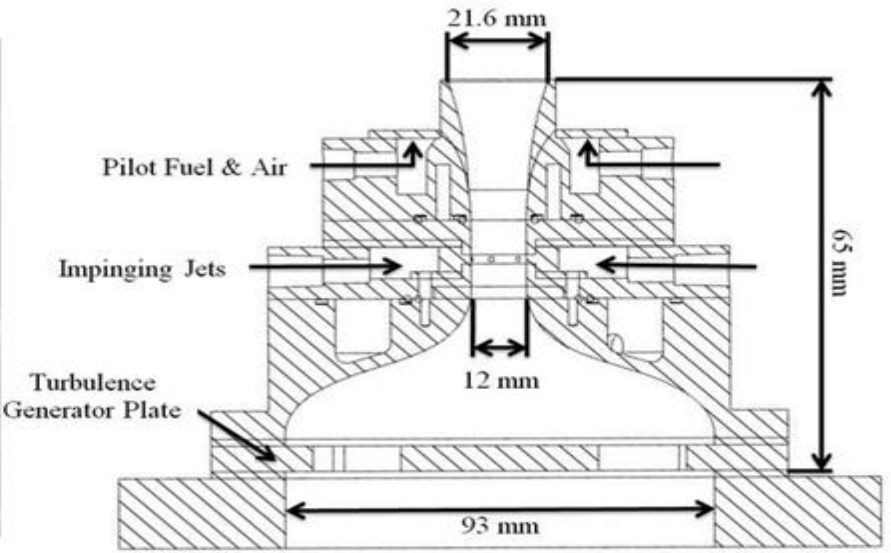

(b)

Figure 2. An image of the burner operating at $\operatorname{Re}_{\mathrm{T}}=22,000$ in (a) and a schematic of the Hi-Pilot burner in (b).

The burner is designed to provide a turbulence level ( $\left.u^{\prime}\right)$ and integral scale $(\lambda)$ that are uniform in space, which avoids ambiguities as to where conditions lie on the regime diagram. This is achieved by expanding the flow at the jet exit, producing a relatively constant downstream turbulence level. Note that this approach avoids a problem inherent to experiments using a straight-sided jet, which exhibit a turbulence level that decays linearly with downstream distance. An additional benefit of expanding the flow at the jet exit is the prevention of flame flashback, as the diverging walls produce gas velocities that increase in the upstream direction.

Turbulence is created with a slotted-contraction device, similar to that of Marshall et al. ${ }^{19,20}$. Premixed reactants impinge on a slotted plate placed upstream of a converging-diverging section; this plate is labeled as the Turbulence Generator Plate in Figure 2b. The plate generates shed vortices, which are then contracted through the converging section. Turbulence is enhanced by the addition of impinging jets of the same equivalence ratio, injected perpendicular to the main flow at the throat of the converging-diverging section. This has the effect of breaking up the large eddies shed by the slotted plate, as well as adding energy to the turbulence. The impinging jets are operated at $6 \%$ of the main flow rate. Operating conditions for the Hi-Pilot are listed in Table 1 below. Note that case 1 was operated without impinging jets (to reduce the turbulence).

\begin{tabular}{ccccccccc}
\hline Case & $\mathrm{U}_{\mathrm{avg}}(\mathrm{m} / \mathrm{s})$ & $\mathrm{u}^{\prime}(\mathrm{m} / \mathrm{s})$ & $\lambda(\mathrm{mm})$ & $\mathrm{Re}_{\mathrm{T}}$ & $\mathrm{Da}_{\mathrm{T}}$ & $\mathrm{u}^{\prime} / \mathrm{S}_{\mathrm{L}}$ & $N / \delta_{\mathrm{PH}, \mathrm{L}}$ & $\varphi$ \\
\hline 1 & 7.0 & 1.6 & 17 & 1,800 & 39 & 6.7 & 48 & 0.75 \\
2 & 45 & 13 & 25 & 22,000 & 6.6 & 57 & 69 & 0.75 \\
3 & 61 & 22 & 28 & 40,000 & 4.4 & 95 & 77 & 0.75 \\
4 & 106 & 43 & 25 & 69,000 & 2.1 & 183 & 70 & 0.75 \\
\hline
\end{tabular}

Table 1. Operating conditions for methane-air combustion, $\mathrm{T}_{1}=300 \mathrm{~K}, \mathrm{p}=1 \mathrm{~atm}$. 
Table 1 shows that the integral length scale is relatively constant across cases $2-4$, but contracts significantly under the more moderate turbulence of case 1 . The flow field was characterized using a Laser Doppler Velocimeter (LDV) system. An Argon-Ion laser operating at 1.5 Watts (Coherent Innova 90c) and a commercial Doppler burst correlator (TSI FSA 4000) were used to measure the axial component of the jet centerline velocity. The tracer species used in this experiment was $0.5 \mu \mathrm{m}$ alumina-oxide particles, while the optical components and photomultiplier tube consisted of standard commercial LDV equipment (TSI). The LDV focal volume was approximately $5 \mathrm{~mm}$ above the burner centerline.

Simultaneous formaldehyde-OH $\left(\mathrm{CH}_{2} \mathrm{O}-\mathrm{OH}\right)$ PLIF images were acquired by two Andor iStar intensified $\mathrm{CCD}$ cameras binned $(2 \times 2)$ to $512 \times 512$ pixels and firing at $2.5 \mathrm{~Hz}$. The formaldehyde $\left(\mathrm{CH}_{2} \mathrm{O}\right)$ was excited by the third harmonic of a Spectra-Physics Nd:YAG laser operating at $355 \mathrm{~nm}$ and approximately $135 \mathrm{~mJ} / \mathrm{pulse}$. The returning $\mathrm{CH}_{2} \mathrm{O}$ fluorescence was filtered using a high and low pass filter (CG385 and BG3, respectively) transmitting wavelengths between 385 and $490 \mathrm{~nm}$. The $\mathrm{OH}$ beam was excited using a second Spectra-Physics Nd:YAG laser pumping a Sirah dye laser. The dye was tuned to output $566.45 \mathrm{~nm}$, which was then doubled using a $\mathrm{BBO}$ crystal to $283.22 \mathrm{~nm}$ to excite the $\mathrm{Q}_{1}(7)$ transition of $\mathrm{OH}^{21}$. Typical laser power was $4.5 \mathrm{~mJ} / \mathrm{pulse}$ at 283.22 $\mathrm{nm}$. The camera capturing $\mathrm{OH}$ fluorescence was equipped with a bandpass filter centered at $310+/-5 \mathrm{~nm}$. Gate times for both cameras were limited to $100 \mathrm{~ns}$ and the laser pulses were separated by $500 \mathrm{~ns}$ to avoid cross-talk ${ }^{22}$. A diagram depicting the simultaneous PLIF imaging setup is provided below in Figure 3. Note that only one set of sheet forming optics is shown, for the sake of clarity; however, the $\mathrm{OH}$ and $\mathrm{CH}_{2} \mathrm{O}$ laser sheets were formed with two separate sets of sheet-forming optics, and were overlapped before being focused over the burner centerline.

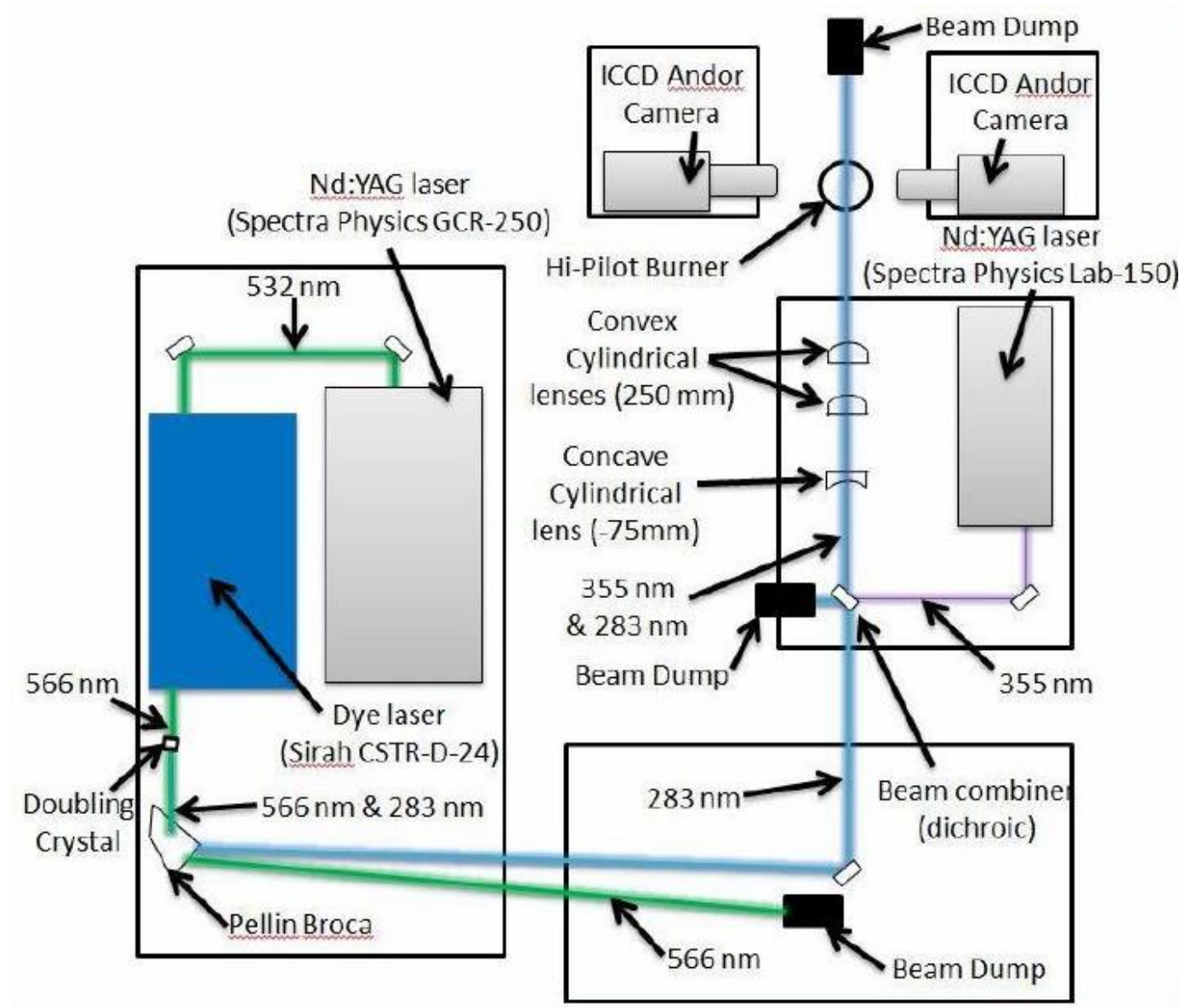

Figure 3. Schematic of the simultaneous $\mathrm{CH}_{2} \mathrm{O}-\mathrm{OH}$ PLIF system. 
The reaction zone thickness is defined to be the width of the $\mathrm{CH}_{2} \mathrm{O}-\mathrm{OH}$ overlap layer at $50 \%$ of its maximum value (FWHM). Previous studies ${ }^{23-28}$ have also used the overlap of $\mathrm{OH}$ and $\mathrm{CH}_{2} \mathrm{O}$ or $\mathrm{HCO}$ to define the reaction layer. This is because the primary pathway for $\mathrm{HCO}$ production (and subsequently heat release) involves the formaldehyde- $\mathrm{OH}$ product (abbreviated as FOP). Specifically, $\mathrm{OH}+\mathrm{CH}_{2} \mathrm{O} \Rightarrow \mathrm{HCO}+\mathrm{H}_{2} \mathrm{O}$, and thus the rate of production of $\mathrm{HCO}$ is proportional to $[\mathrm{OH}] \mathrm{x}[\mathrm{CH} 2 \mathrm{O}]$. Figure 4 shows $\mathrm{CHEMKIN} \mathrm{profiles} \mathrm{calculated} \mathrm{for} \mathrm{a} \mathrm{freely}$ propagating laminar premixed methane-air flame $(\Phi=0.75)$. The FOP thickness was found to be $0.18 \mathrm{~mm}$ in the CHEMKIN simulations of a premixed laminar flame, and was used to normalize the PLIF thickness measurements.

$\mathrm{Li}$ et al. ${ }^{29}$ showed that $\mathrm{CH}_{2} \mathrm{O}$ can also be used as a marker of the preheat zone. From initial PLIF images, it was observed that at an intensity ratio of roughly $35 \%$ of the local maximum intensity, the signal rapidly decayed to zero. This threshold was chosen to represent the reactant-side boundary of the preheat zone. The preheat zone thickness is defined here as the width of the $\mathrm{CH}_{2} \mathrm{O}$ signal from its $35 \%$ point on the reactant side to the leading edge of the reaction zone (defined above as the half-maximum value on the reactant side). The leading edge of the flame was selected to be where formaldehyde signal is $35 \%$ of its maximum value because CHEMKIN shows that at this location the gas temperature is $550 \mathrm{~K}$. This temperature was selected to be the upstream boundary of the preheat zone. The laminar value of the preheat zone thickness computed by CHEMKIN was $0.36 \mathrm{~mm}$, which was used to normalize subsequent PLIF

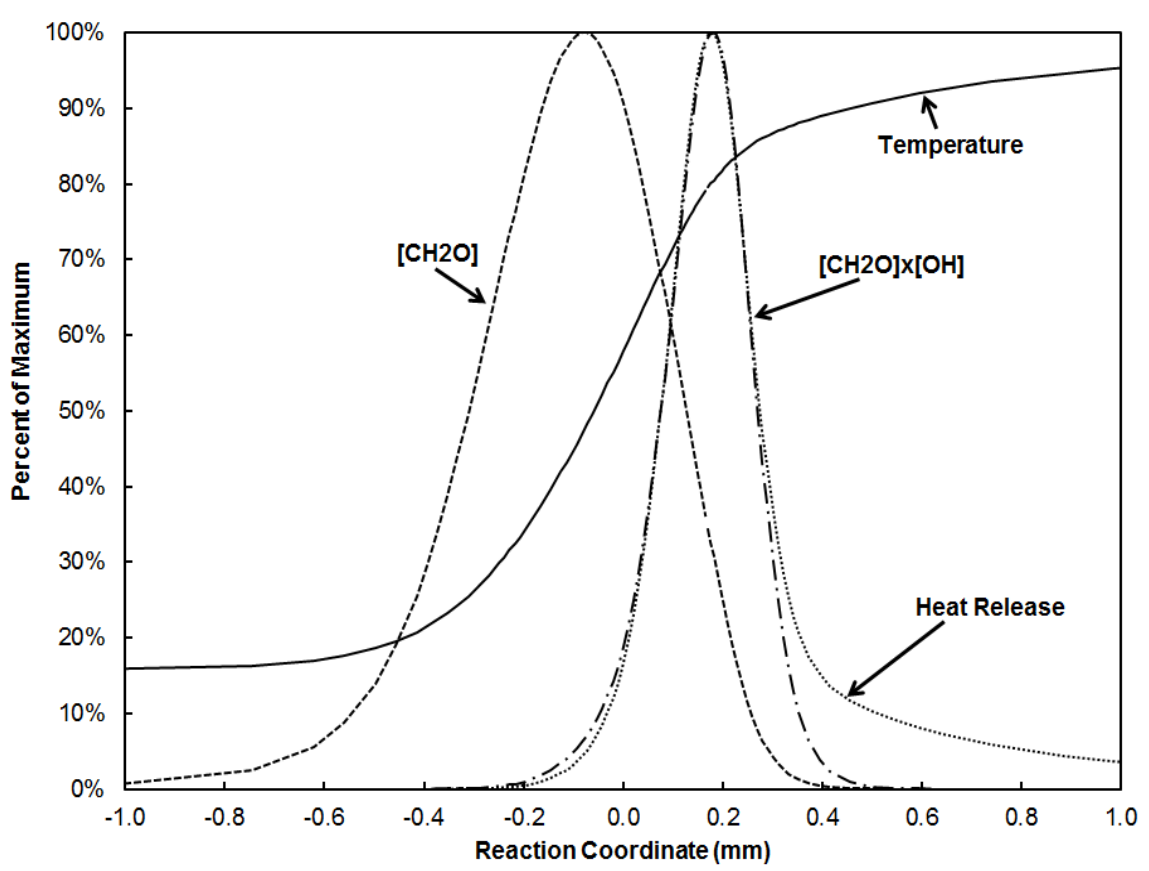

Figure 4. CHEMKIN laminar flame computations showing that formaldehyde marks the preheat zone while the overlap of formaldehyde-OH marks the reaction zone. measurements.

\section{B. Image processing}

Reaction zone thicknesses are identified as the full-width at half-maximum of the pixel-by-pixel product of the $\mathrm{OH}$ and $\mathrm{CH}_{2} \mathrm{O}$ images. Prior to the multiplication process several steps were taken to improve the quality of the raw images. First background noise was removed from the raw $\mathrm{OH}$ and $\mathrm{CH}_{2} \mathrm{O}$ images, which were then corrected for variations in laser sheet intensity. After this adjustment a combination of median and level-set filters ${ }^{30,31}$ were applied to remove salt and pepper noise. Following this filtering the $\mathrm{OH}$ images were transformed so that they would register to the $\mathrm{CH}_{2} \mathrm{O}$ images. The transform matrix was produced by imaging a double-sided grid target with both cameras. This target, which consisted of crosses printed on both sides of a thin transparent sheet, was placed in the cameras' field of view and was aligned with the laser sheets. Finally, the pixel-by-pixel multiplication of these modified images was performed. 
An example of how the reaction zone is obtained from filtered $\mathrm{OH}$ and $\mathrm{CH}_{2} \mathrm{O}$ images is provided in Figure 5 below.
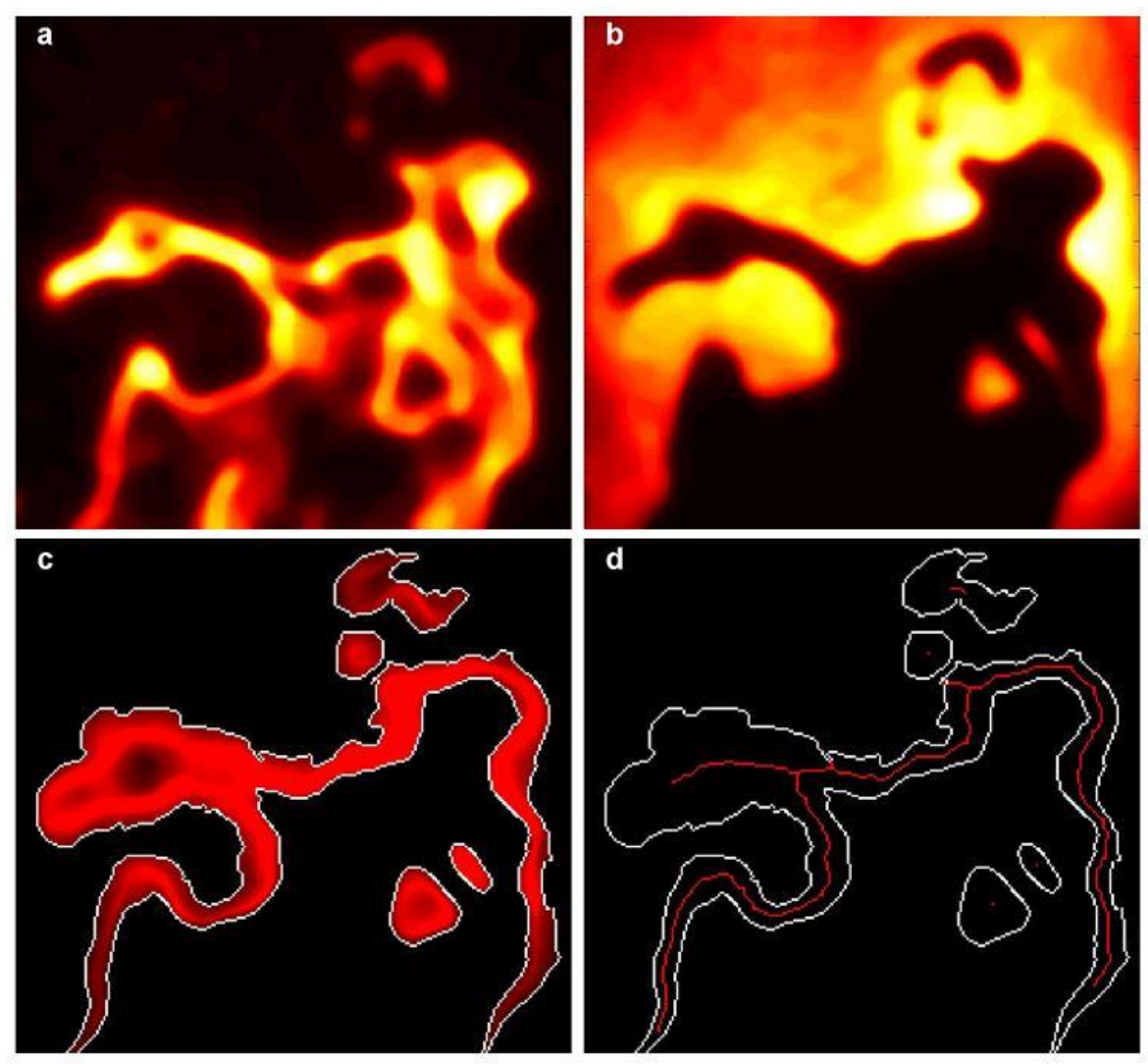

Figure 5. (a) and (b) display filtered, instantaneous PLIF image of $\mathrm{CH}_{2} \mathrm{O}$ and $\mathrm{OH}$, respectively. (c) exhibits the masked and locally thresholded pixel-by-pixel product of the $\mathrm{CH}_{2} \mathrm{O}$ and $\mathrm{OH}$ images presented in (a) and (b). While (d) displays the edge and the skeleton associated with the reaction zone shown in (c).

Panel (c) of Figure 5 is a prime example of how the reaction zone can assume any arbitrary shape and orientation. Due to this vast variation in shape and orientation the full-width at half-maximum (FWHM) of the product images is obtained by implementing a local thresholding method. However, prior to applying this local thresholding method, low level noise (which is amplified through the multiplication process) is removed from the product images by multiplying them with a binary mask, which is produced via an edge detection scheme. To generate this mask the edge of the reaction zone is first identified using the Sobel edge detection method. The binary mask is then generated by setting all pixels within the edges of the reaction zone to one and all pixels outside to zero.

Once the overlap image has been masked, a global threshold is generated based on the standard deviation of the signal. All pixels with an intensity count greater than one and a half standard deviations above the minimum signal are set to one, while the rest are set to zero. A skeleton (such as the one depicted by the red line in Figure 5d) is then formed from this newly binarized image. This skeleton is used for local thresholding, since it represents a first guess at where the flame lies. Each pixel in the product image is compared to the nearest skeleton pixel; that is, each pixel is thresholded not relative to a field constant, but to the value of a point in the image where we believe a flame is located. The thresholding process is repeated several times, using the previous result as the input to the next iteration, and typically converges to a solution in approximately three iterations. In this way, thresholding the 
image is done locally instead of globally, which helps to avoid errors introduced by naturally occurring variations in intensity of $\mathrm{CH}_{2} \mathrm{O}-\mathrm{OH}$ overlap in the field of view (FOV).

Once the product images were properly thresholded an average reaction and preheat zone thickness was calculated for each image as follows. First, the distance between each pixel on the skeleton and the nearest pixel on an edge of the reaction zone was determined. Then, these distances where multiplied by a factor of two to account for the fact that the skeleton lies along the center of the reaction zones. Finally, summing these distances over the whole skeleton in a particular image and subsequently dividing this summation by the length of that skeleton produced an average thickness value for that image. The average preheat zone thickness for a specific image was computed in a similar fashion; the only difference being that the $\mathrm{CH}_{2} \mathrm{O}$ signal was first modified to exclude regions identified as reaction zone (i.e. the $\mathrm{CH}_{2} \mathrm{O}-\mathrm{OH}$ overlap signal was subtracted from the $\mathrm{CH}_{2} \mathrm{O}$ signal).

\section{Results}

This section provides details about flow-field measurements and both qualitative and quantitative flame properties for each of the four cases described in Table 1 above.

\section{A. LDV Flow-field Characterization}

Turbulence level and integral scale measurements were made with the laser velocimeter system and the results are listed in Table 1. For each case in the Hi-Pilot Test Matrix, 4-6 LDV measurements consisting of 500,000 samples each were collected. Autocorrelations were computed using the normalized slotting method of Mayo et al..$^{32-34}$ The resulting averaged autocorrelation functions for each case are shown in Figure $6 . \quad$ The corresponding length scales, defined as the integral of the autocorrelation curve, are given in Table 1. Figure 6 demonstrates that the Hi-Pilot produces a uniform length scale across all operating conditions. For most cases the integral scale was between 25 and $28 \mathrm{~mm}$. Note that LDV measurements provide an integral time scale, which is converted to a length scale using

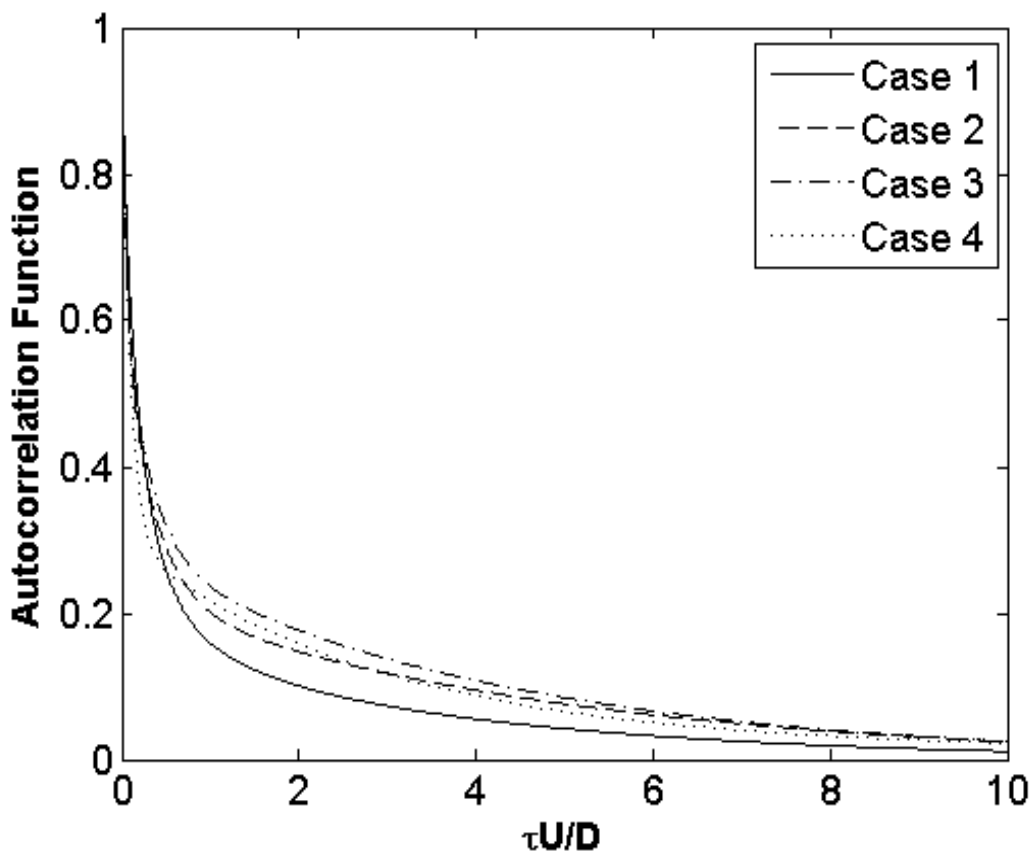

Figure 6. Autocorrelation function for the Hi-Pilot Test Cases. Taylor's "frozen turbulence" hypothesis.

\section{B. $\mathrm{CH}_{2} \mathrm{O}-\mathrm{OH}$ PLIF results}

This section discusses patterns identified in instantaneous PLIF images of $\mathrm{CH}_{2} \mathrm{O}$ and $\mathrm{OH}$ as well as several measurements made from these images. 


\section{a. $\mathrm{OH}, \mathrm{CH}_{2} \mathrm{O}$, and $\mathrm{CH}_{2} \mathrm{O}-\mathrm{OH}$ overlap images}

To provide a holistic view of the flame, a single large field of view (22 $\mathrm{mm} \times 36 \mathrm{~mm}$ ) PLIF image is displayed for each of the four cases in Figure 7 below. Note however that in general this FOV was not large enough to image the flame from base to tip.
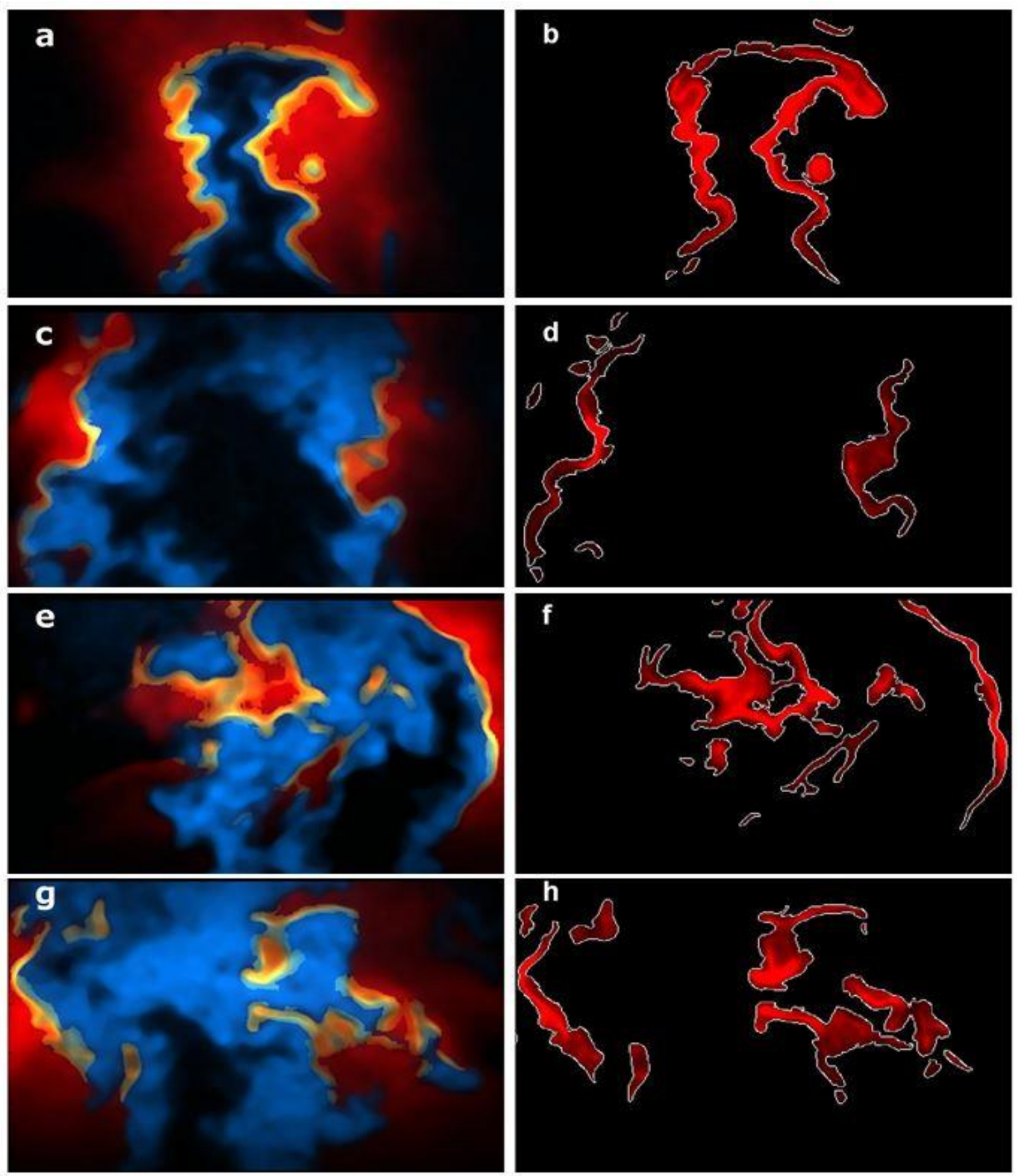

Figure 7. Panels (a), (c), (e), and (g) show post-processed, instantaneous PLIF image with a $22 \mathrm{~mm} \times 36 \mathrm{~mm}$ field of view for cases $1-4$, respectively. Blue indicates $\mathrm{CH}_{2} \mathrm{O}$ signal, red indicates $\mathrm{OH}$ signal, and yellow indicates the reaction zone. Panels (b), (d), (f), and (h) display the reaction zones for cases $1-4$, respectively. The lower edge of each image is $5 \mathrm{~mm}$ above the burner. The centerline of each image is the burner's centerline. 
The blue regions (which represent $\mathrm{CH}_{2} \mathrm{O}$ signal) in the left panels of Figure 7 show that the preheat zone thickness tends to increase with increasing turbulence intensity. Additionally, Figure 7 also indicates that the preheat zone thickness increases with height above burner (HAB). This trend is particularly clear in panel $(\mathrm{g})$ of Figure 7. Here, for heights greater than $20 \mathrm{~mm}$ above the burner, $\mathrm{CH}_{2} \mathrm{O}$ is found throughout the entire central region of the flame. Similar results were also observed by Bo et al. in a porous-plug/jet burner ${ }^{36}$. Variations in preheat zone thickness with turbulence intensity and HAB are discussed in greater detail in section III.B.b below.

In contrast to the preheat zone, trends associated with the reaction zone thickness are more difficult to extract from Figure 7. This is because segments of both thick and thin reaction zones can be seen throughout the entire FOV for each of the four cases. However, Figure 7 does provide two clear trends between the reaction zone thickness and the turbulence intensity. Namely, as the turbulence Reynolds number increases the reaction zones become more contorted and are more likely to possess regions of local extinction. These trends are quantified by our tortuosity $(\Omega)$ and burning fraction $(B F)$ parameters, respectively, and are presented in sections III.F and III.D below. Furthermore, section III.B.b provides a more in depth discussion on how turbulence intensity and HAB affect reaction zone thicknesses.

To obtain quantitative data from the instantaneous PLIF images, two zones of relatively high resolution $(40 \mu \mathrm{m} / \mathrm{pixel})$ were selected for each case. The field of view for these zones was $13 \mathrm{~mm} \times 20 \mathrm{~mm}$ and their relative spatial locations are depicted in Figure 8 below.

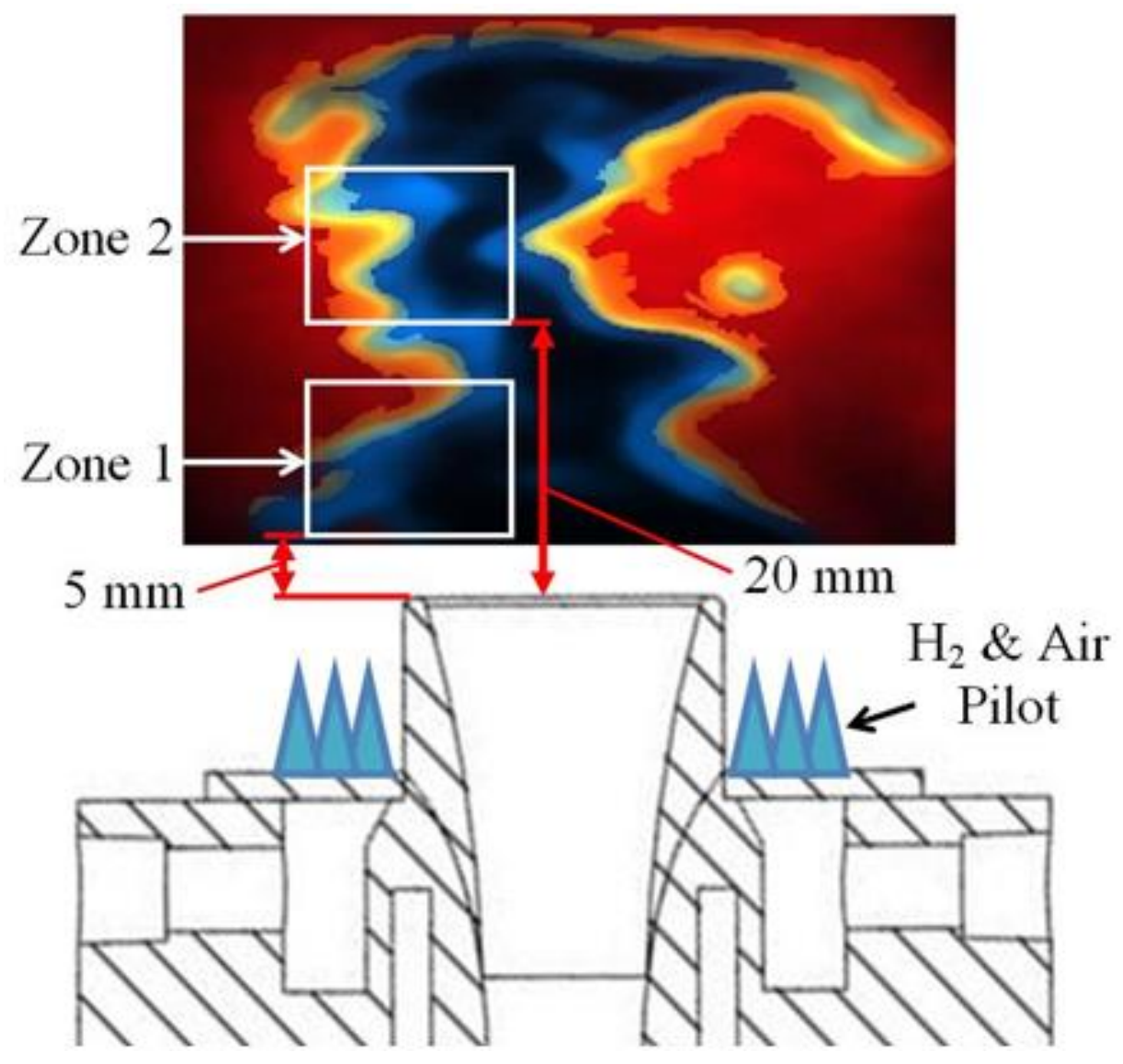

Figure 8. Diagram depicting the relative locations of zones 1 and 2. 
As Figure 8 shows, zone 1 and zone 2 span regions between $5 \mathrm{~mm}$ and $18 \mathrm{~mm}$ and between $20 \mathrm{~mm}$ and 33 $\mathrm{mm}$ above the burner, respectively. Examples of typical PLIF images from zone 1 and zone 2 for each case are provided in Figures 9 and 10, respectively. Note that the image in Figure 8 above has a field of view of $22 \mathrm{~mm}$ by $36 \mathrm{~mm}$.
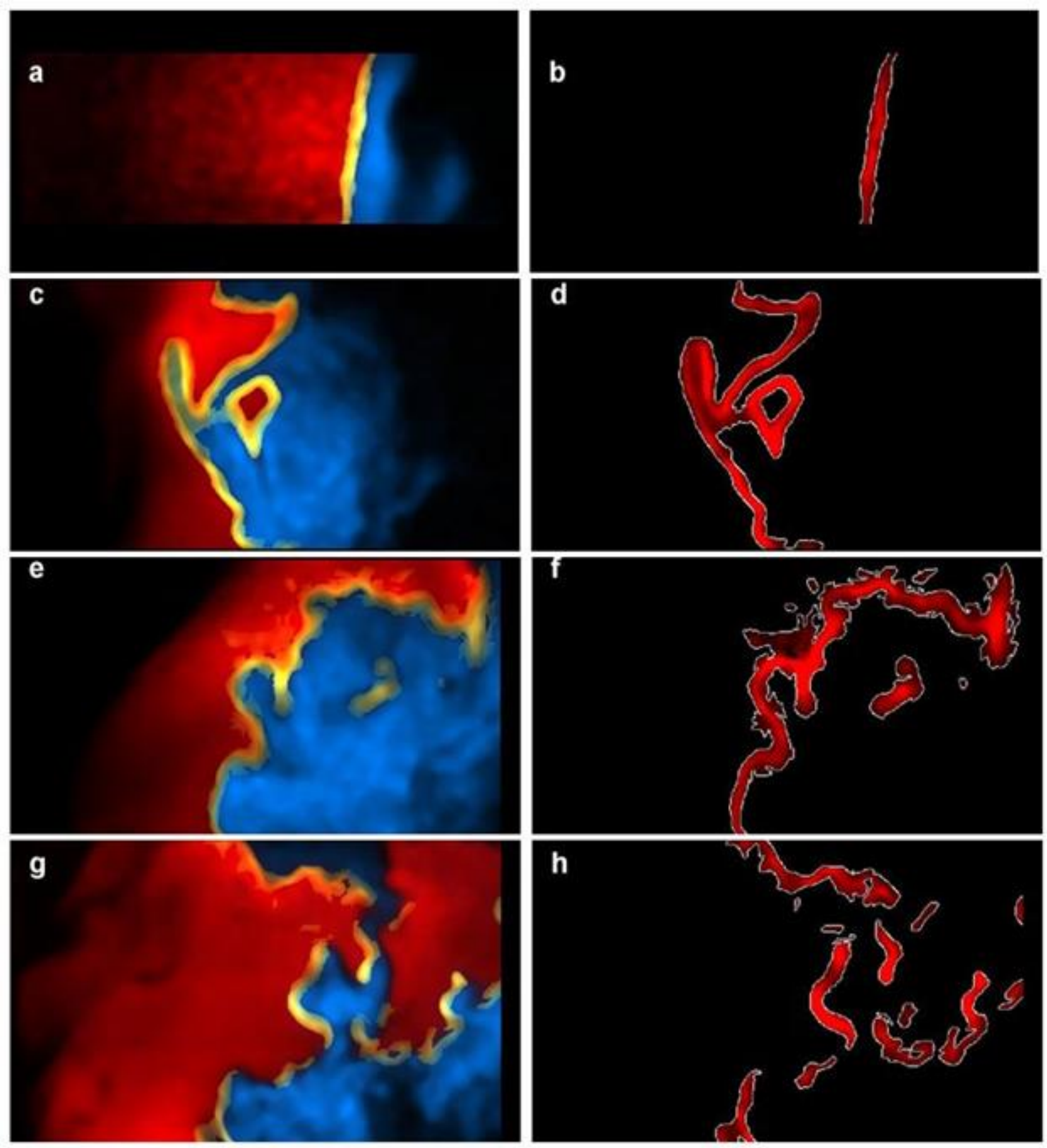

Figure 9. Panels (a), (c), (e), and (g) show post-processed, instantaneous PLIF images from zone 1 for cases $1-4$, respectively. Blue indicates $\mathrm{CH}_{2} \mathrm{O}$ signal, red indicates $\mathrm{OH}$ signal, and yellow indicates the reaction zone. Panels (b), (d), (f), and (h) display the reaction zones for cases $1-4$, respectively. 

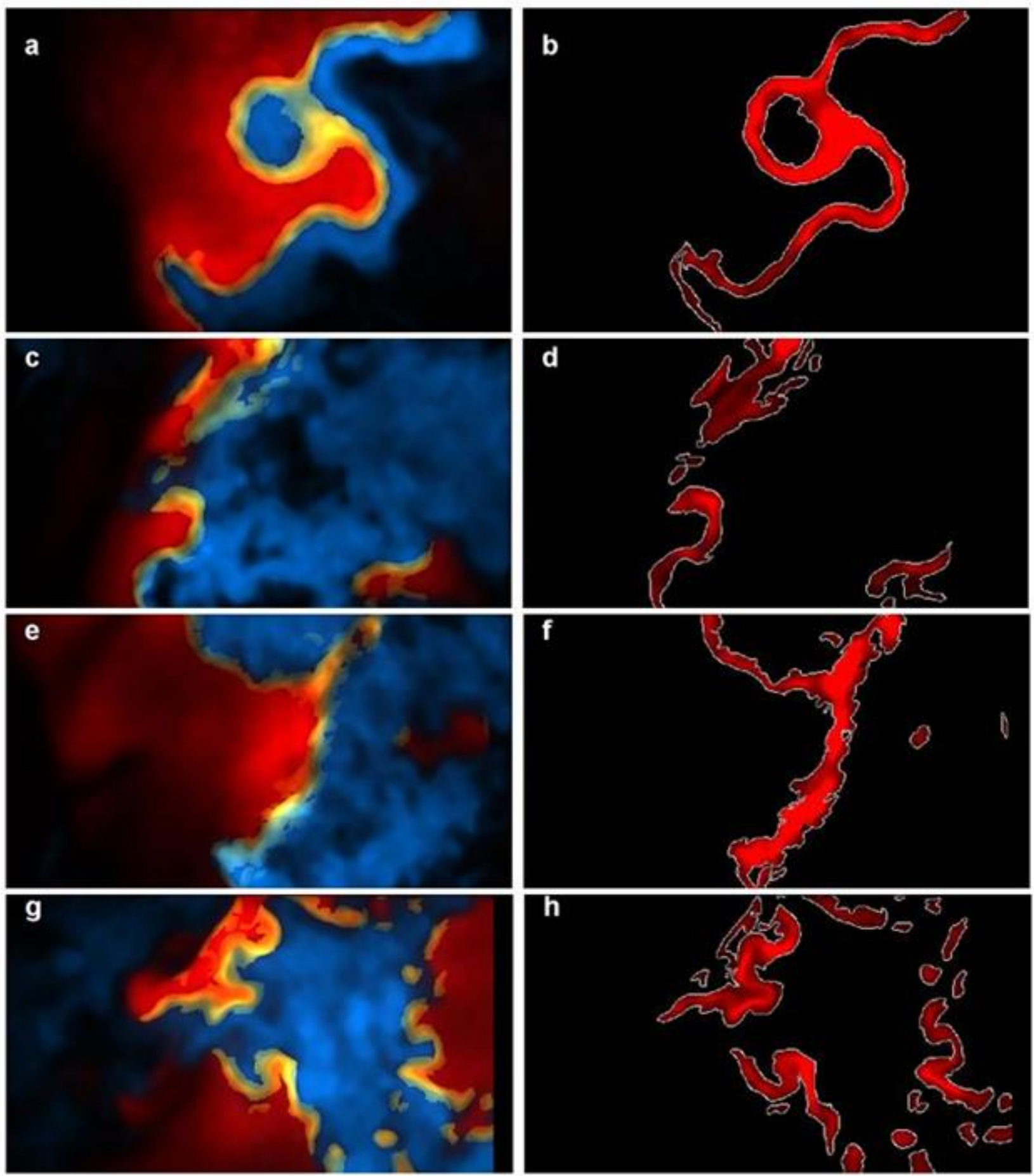

Figure 10. Panels (a), (c), (e), and (g) show post-processed, instantaneous PLIF images from zone 2 for cases 1 - 4, respectively. Blue indicates $\mathrm{CH}_{2} \mathrm{O}$ signal, red indicates $\mathrm{OH}$ signal, and yellow indicates the reaction zone. Panels (b), (d), (f), and (h) display the reaction zones for cases $1-4$, respectively. 
These higher resolution images emphasize the patterns seen in Figure 7. That is, as turbulence intensity increases the preheat zone thickens, and the reaction zone layers become more convoluted and possess a greater number of discontinuities (i.e. regions of local extinction). For instance, panels (a)-(f) of Figure 9 show continuous reaction layers for cases $1-3$. On the other hand, multiple regions of local extinction can be identified in the sample image provided for case 4 in zone 1 (i.e. panels (g) and (h) of Figure 9). This trend is echoed in zone 2. Specifically, with the exception of case 2 (shown in panels (c) and (d) of Figure 10), the reaction zone layers remain rather continuous until case 4 (shown in panels $\left(\mathrm{g}\right.$ ) and (h) of Figure 10). Discontinuities in the $\mathrm{CH}_{2} \mathrm{O}-\mathrm{OH}$ overlap layer were also observed by Kariuki et al. in a methane-air flame stabilized on a bluff body ${ }^{28}$. However, rather than increasing the turbulence level they reduced the equivalence ratio until the flame was near its lean blow-off limit. Only at this limit did they observe clear discontinuities in the $\mathrm{CH}_{2} \mathrm{O}-\mathrm{OH}$ overlap layer.

\section{b. Preheat and reaction zone thickness}

Over 250 PLIF image pairs of $\mathrm{OH}$ and $\mathrm{CH}_{2} \mathrm{O}$ were acquired for each case. Average preheat and reaction zone thicknesses were determined for each of the $\mathrm{CH}_{2} \mathrm{O}$ PLIF images and the product of the $\mathrm{OH}$ and $\mathrm{CH}_{2} \mathrm{O}$ PLIF images, respectively. The details of how these average thicknesses were computed for each image are provided in section II.B above. The datum points in Figure 11 below represent an ensemble average of the preheat zone thicknesses over all images taken for each case.

The error bars in Figure 11 are based on the $95 \%$ confidence interval of each data set. Figure 11 clearly shows that the preheat zone thickness initially increases with turbulence Reynolds number. Yet, the trends in Figure 11 imply that the preheat zone thickness levels off for turbulence Reynolds numbers above 20,000. This asymptotic behavior makes sense, as the area encapsulated by the flame is finite. At turbulence Reynolds numbers above 40,000 (panels (e) and (g) of Figure 7) $\mathrm{CH}_{2} \mathrm{O}$ exists throughout the entire central region of the flame.

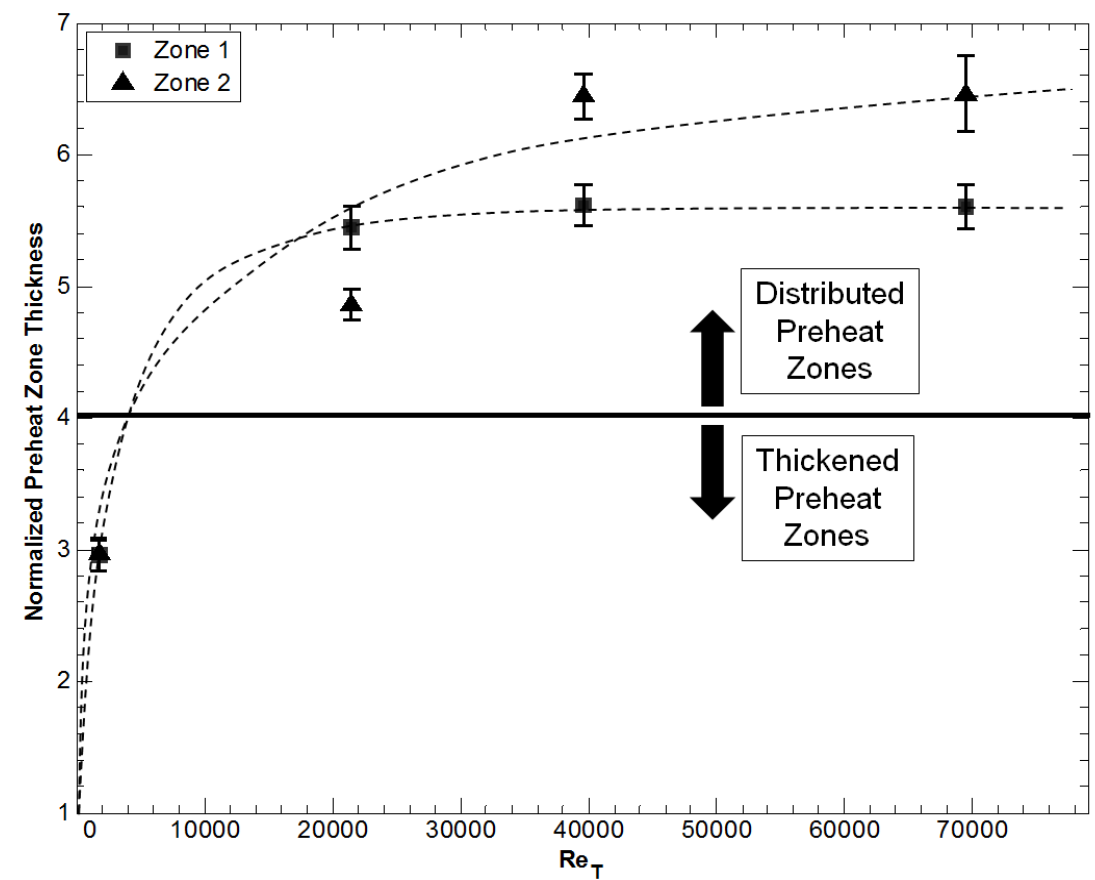

Figure 11. Average preheat zone thickness normalized by the laminar preheat zone thickness as computed in Chemkin $(0.36 \mathrm{~mm})$ for zones 1 and 2 as a function of turbulence Reynolds number.

With the exception of case 2, Figure 11 also suggests that the preheat zone is thicker at greater heights above the burner. The observation that the preheat zone of case 2 is thinner at greater heights above the burner is a result of its flame structure. That is, in zone 2 of case 2 the flame structure often displays fragments of reaction zone encapsulated by $\mathrm{CH}_{2} \mathrm{O}$. Such an instance is displayed in Figure 12 below. 


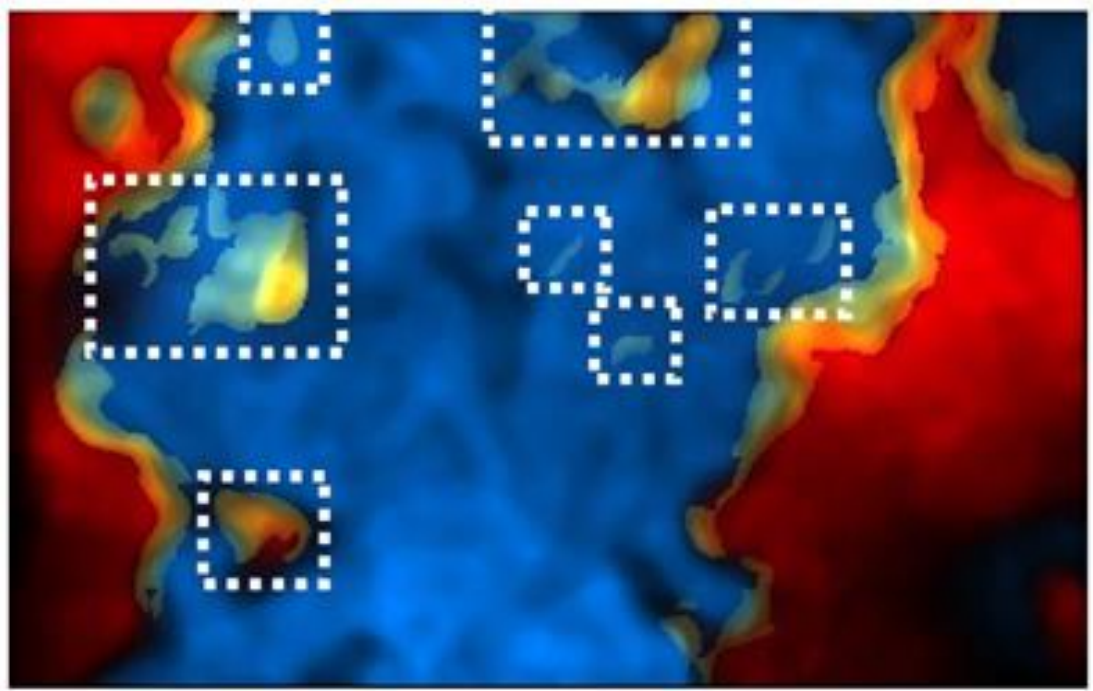

Figure 12. Post-processed, instantaneous PLIF image taken for case 2 in zone 2. Blue indicates $\mathrm{CH}_{2} \mathrm{O}$ signal, red indicates $\mathrm{OH}$ signal, and yellow indicates the reaction zone. The dotted, white rectangles highlight regions of reaction zone surrounded by $\mathrm{CH}_{2} \mathrm{O}$.

The isolated pockets of reaction zone highlighted by the dotted, white rectangles in Figure 12 have the effect of fragmenting the $\mathrm{CH}_{2} \mathrm{O}$ layer, which ultimately leads to a lower average preheat zone thickness.

An increase in preheat zone thickness with height above burner can be associated with the fact that the flame brush typically widens downstream of the burner's exit, which is a consequence of the burner's diverging exit nozzle. Additionally, this trend could potentially be attributed to elevated turbulence levels at moderate heights above the burner, which were observed in similar jet burners ${ }^{14,36}$. However, in order to validate this hypothesis, characteristics of the Hi-Pilot flow field must be assessed at regions downstream of its exit.

The observed increase in preheat zone thickness with height above burner could potentially be described by a unique view of turbulence-flame interactions. That is, the role of turbulence in excessively broadening the preheat zone may be two fold. Typically, preheat zone broadening is thought to be a result of the enhanced scalar mixing and diffusivity associated with turbulent flows ${ }^{18}$. However, if turbulence levels are sufficiently high such that holes appear within the reaction zone hot product may be allowed to mix with the cool reactants. Mixing of hot products with reactants would permit relatively large distributions of higher temperatures within the unburnt gas mixture. Based on Mallard and LeChatelier's thermal two-zone model ${ }^{37,38}$, the existence of larger regions of high temperatures within the unburnt gas mixture would imply a thicker preheat zone.

As mentioned above, this mixing of hot products with reactants could offer an additional explanation as to why the preheat zone tends to be thicker at greater heights above the burner. Namely, holes in the reaction zone near the burner's exit, which are observed in zone 1 of case 4 (see panels (g) and (h) of Figure 9), could enable hot products to mix with cool reactants as they are carried downstream. Hence, it is possible that the hot products will have sufficiently mixed with the cool reactants at moderate heights above the burner, subsequently enabling the preheat zone to encompass the entire interior of the flame at these heights. However, in order to justify this theory, time resolved measurements of such flame phenomena would have to be captured. Such measurements are planned for the future. 
The horizontal solid line in Figure 11 represents the boundary of 'thickened' and "globally distributed" preheat zones. This boundary is defined by the inequality:

$$
\delta_{\mathrm{PH}, \mathrm{T}} / \delta_{\mathrm{PH}, \mathrm{L}}>4
$$

That is, the preheat zones associated with a particular case are deemed "globally distributed" when the average preheat zone thickness exceeds four times the laminar value. This suggests that cases $2-4$ all possess "globally distributed" preheat zones, while case 1's preheat zones are considered to be thickened. The definition of this boundary is supported by the PLIF images displayed in Figures 9 and 10. The $\mathrm{CH}_{2} \mathrm{O}$ layer for case 1 (shown in panel (a) of Figures 9 and 10) appears relatively thin. Conversely, the $\mathrm{CH}_{2} \mathrm{O}$ layers for the other three cases are quite thick and are seen to fill up nearly half of the FOV shown in panels (c), (e), and (g) of Figures 9 and 10. Thus, using Eq. (5) to define the border of thickened and "globally distributed" preheat zones seems reasonable.

As in Figure 11, the data displayed in Figure 13 is produced by averaging the reaction zone thicknesses over all images taken for each case. The error bars in Figure 13 represent the measurement uncertainty induced by having a finite pixel resolution of $40 \mu \mathrm{m} / \mathrm{pixel}$. This error value was chosen because it exceeds the uncertainty computed from the $95 \%$ confidence interval. As with the preheat zone thicknesses, Figure 13 implies that the reaction zone thicknesses initially rise with increasing levels of turbulence. However, Figure 13 demonstrates that increasing the turbulent Reynolds number beyond roughly 30,000 leads to a thinning of the reaction zones. Possible explanations for this trend are as

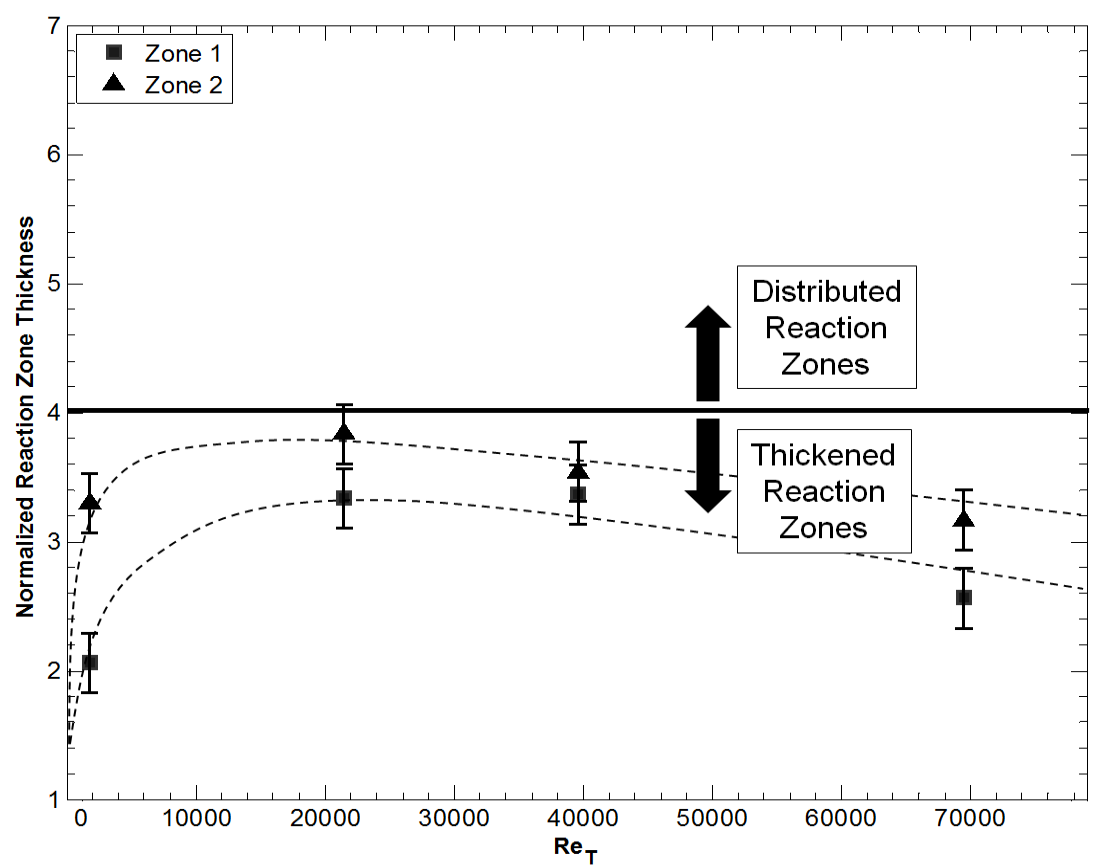

Figure 13. Average reaction zone thickness normalized by the laminar reaction zone thickness as computed in CHEMKIN $(0.18 \mathrm{~mm})$ for zones 1 and 2 as a function of turbulence Reynolds number.

1. As discussed above in section III.B.a and below in section III.D, the amount of discontinuities in the reaction zone layers increases with turbulence intensity. In other words, increasing the turbulent Reynolds number has the effect of shredding the flame into relatively small fragments. Panel (h) of Figures 9 and 10 offer an excellent example of a shredded flame. Often times these fragments are relatively thin. Hence, on average, the overall reaction zone thickness of these shredded flames is less than those with more continuous layers.

2. It is highly likely that the shear strain rate exerted on the flame at the turbulence levels found in cases 3 and 4 is excessively high. As suggested by Driscoll ${ }^{5}$, the exertion of significant amounts of strain rate on reaction zones could cause them to become thinner and shredded. However, validation of this premise requires the simultaneous collection of both flow field and reaction zone information, which was unavailable in the present study. 
Another pattern presented in Figure 13 is that the thickness of the reaction zone increases with height above burner. As in the case of the preheat zone thickness this could be a result of increased turbulence levels at moderate heights above the burner. Yet, as mentioned above, properties of the flow field at regions downstream of the HiPilot burner's exit are necessary to justify this explanation. Such properties were unavailable for the current study.

Similar to the solid horizontal line in Figure 11, the solid line in Figure 13 indicates the boundary of thickened and "globally distributed" reaction zones. This boundary is defined by the inequality:

$$
\delta_{\mathrm{RZ}, \mathrm{T}} / \delta_{\mathrm{RZ}, \mathrm{L}}>4
$$

That is, the reaction zones of a particular case are designated as being "globally distributed" when that case's average reaction zone thickness exceeds four times the laminar reaction zone thickness. Thus, from Figure 13, it is apparent that on average all of the cases lie within the thickened reaction zone regime. That is, on average, none of the cases as a whole can be identified as falling within a globally distributed reaction zone regime. However, as will be shown in section III.C below, up to $45 \%$ of the reaction zones in a specific case are considered to be "locally distributed."

\section{Percent of distributed reaction zones}

The measured $\mathrm{CH}_{2} \mathrm{O}-\mathrm{OH}$ overlap regions were observed to have regions that behaved like thickened flamelets and also regions that showed larger distributed reaction zones. In order to quantify the amount of locally distributed regions a parameter was defined as given in Eq. (7) below:

$$
\text { locally distributed } \equiv\left\{\begin{array}{l}
\frac{\delta_{R Z, T}}{\delta_{R Z, L}}>4 \\
\frac{\text { Length }}{\delta_{R Z, T}}<4
\end{array}\right.
$$

The same skeleton used in determining the reaction zone thickness is also used to compute this parameter. At each point on the skeleton the distributed parameter was evaluated inside a 40 x 40 pixel neighborhood to determine if the flame was locally thick or locally distributed. An example image is shown in Figure 16, where the white skeleton indicates the regions that are determined to be thickened flamelets.

Figure 17 shows the calculated values of percentage of locally distributed reaction regions as a function of turbulent Reynolds number. As seen in the previously discussed data the flame exhibits more locally distributed regions downstream in zone 2 than in zone 1. Additionally, the flame shows an increase in locally distributed regions as Reynolds number increases before reducing as the flame experiences local extinctions. However, it appears that the

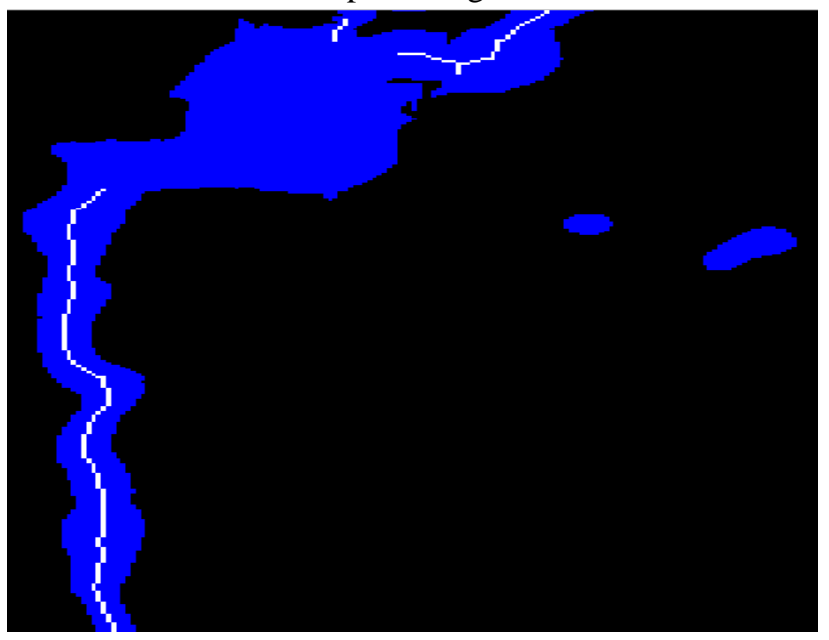

Figure 16. Example of distributed reaction zone parameter marking. White skeleton lines indicate the region is locally a thickened flamelet. The remaining regions are designated as locally distributed reactions. 


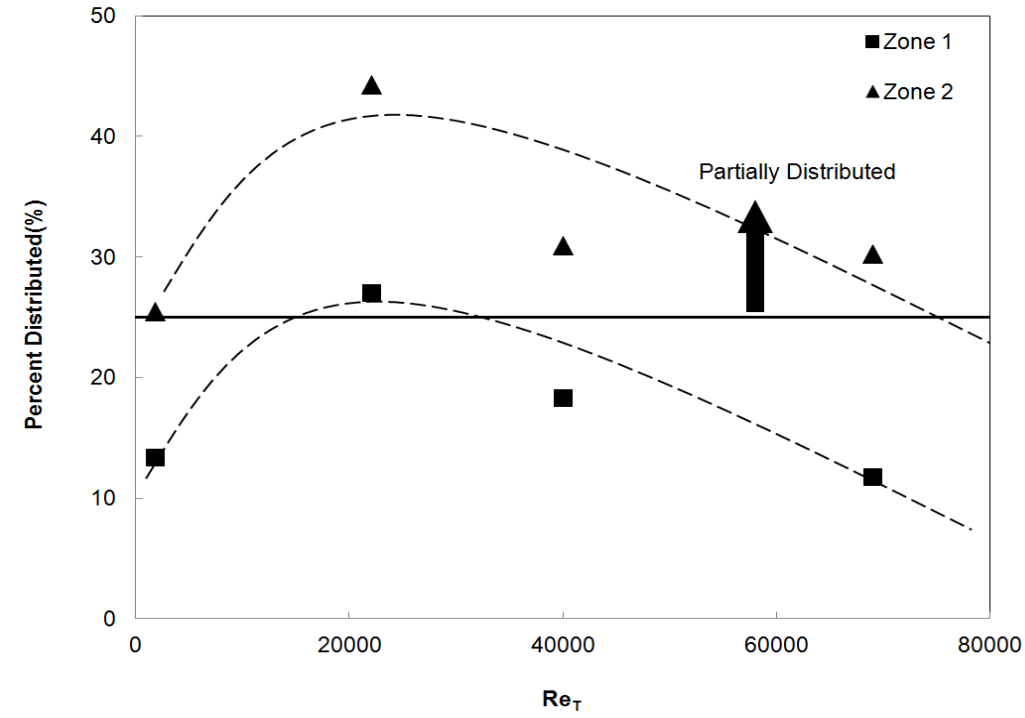

Figure 17. Percentage of locally distributed reaction regions as a function of turbulent Reynolds number. Initially increasing with increasing $\mathrm{Re}_{\mathrm{T}}$, the percentage of distributed regions decreases slightly prior to the onset of local flame extinction. decrease in locally distributed regions occurs before the onset of local extinction. Thus while on average case 3 is partially distributed, it is less so than case 2 .

Cases that fall above the solid, horizontal line in Figure 17 are consisted to, on average, possess "partially distributed" reaction zones. A single reaction zone is deemed partially distributed if more than $25 \%$ of that reaction zone is identified as being locally distributed. Thus, from Figure 17 it is apparent that both zones of case 2 and zone 2 of cases 3 and 4 are partially distributed.

\section{Burning fraction Measurements}

In order to determine the degree of local extinction in the various cases, the "burning fraction" of the flames was evaluated. The burning fraction was defined to be the amount of $\mathrm{CH}_{2} \mathrm{O}$ on or near a reaction zone, divided by the total amount of $\mathrm{CH}_{2} \mathrm{O}$ in the field of view:

$$
B F=\frac{\mathrm{CH}_{2} \mathrm{O} \text { Burning }}{\text { Total } \mathrm{CH}_{2} \mathrm{O}}
$$

Of course, a large fraction of the $\mathrm{CH}_{2} \mathrm{O}$ in any given PLIF image will consist of the "cold edge" boundary, marking the reactant side and the start of the preheat zone. Including this quantity in the denominator above would lead to artificially low burning fractions, and a distorted view of the degree of extinction. The best solution was found to be breaking the image into multiple distinct objects and eliminating any objects not very near a reaction zone at some point along the surface. The problem, and its solution procedure, is clearly illustrated below in Figure 14. On the left is the full $\mathrm{CH}_{2} \mathrm{O}$ edge, and in the middle is the reaction zone edge. Clearly, not every pixel in the $\mathrm{CH}_{2} \mathrm{O}$ frame should be considered when evaluating burning fraction. The right frame illustrates the processed $\mathrm{CH}_{2} \mathrm{O}$ edge, referred to as the "hot edge." It is evident that the procedure described above works as anticipated in eliminating the 'cold edges' from the image.
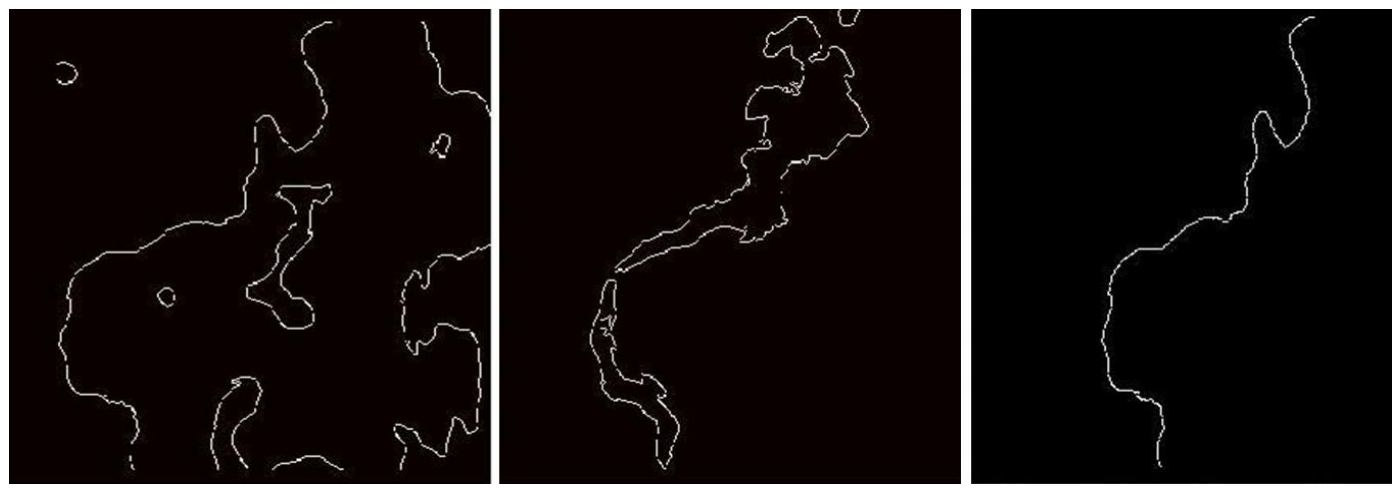

Figure 14. Left: Original $\mathrm{CH}_{2} \mathrm{O}$ edge; Center: Reaction Zone edge; Right: “Hot” $\mathrm{CH}_{2} \mathrm{O}$ edge. 
Once the $\mathrm{CH}_{2} \mathrm{O}$ images have been processed as described above, the burning fraction is evaluated by taking the ratio of pixels on or near a reaction zone to the total number of pixels in the "hot" $\mathrm{CH}_{2} \mathrm{O}$ edge. The results are presented below in Figure 15.

Figure 15 illustrates a clear decrease in the burning fraction of $\mathrm{CH}_{2} \mathrm{O}$ with both increasing Reynolds number and with increasing height above the burner surface. As the Reynold's number is increased, turbulence tears open holes in the flame allowing the entrainment of cold air and the local quenching of reactions. This produces regions in the resulting PLIF signal which contain a $\mathrm{CH}_{2} \mathrm{O}$ boundary and no reaction zone, and thus a decreased burning fraction. Thus, the $\mathrm{CH}_{2} \mathrm{O}$ burning fraction is a marker of the global flame extinction rate.

It is observed that for case 1 conditions $\left(\operatorname{Re}_{\mathrm{T}}=1,800\right)$ a nearly continuous reaction zone surface is

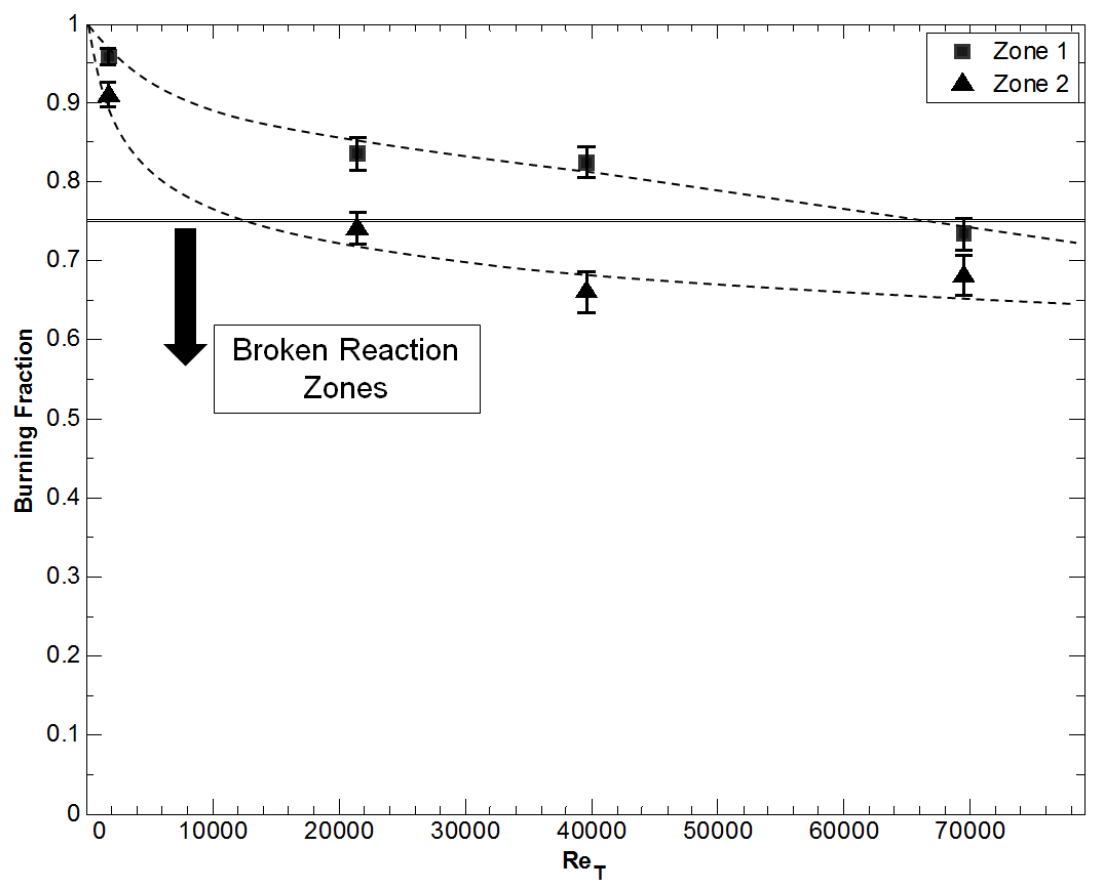

Figure 15. Burning Fraction Results. present. As Reynolds number increases, the $\mathrm{CH}_{2} \mathrm{O}$ burning fraction decreases, although a difference is seen between the two zones interrogated. In Zone 1, near the burner surface, burning fraction continues to decrease with Reynolds Number for all cases. However, Zone 2 exhibits an asymptote around case $3\left(\operatorname{Re}_{\mathrm{T}}=40,000\right)$, suggesting that in this region of the flame a transition occurs somewhere between cases 2 and 3, while cases 3 and 4 are similar. Based on the data, we suggest a burning fraction less than $75 \%$ should correspond to "broken reactions," and this demarcation is indicated by the horizontal line in Figure 15. Based on this definition, four of the eight test cases display broken reaction zones.

\section{E. Regimes associated with the measurements to date}

At present the data set is too limited to plot the regime boundaries. However, it has been possible to determine the regime that is associated with each of the four conditions. A specific case is classified as being globally distributed if its mean thickness exceeds four times the laminar value. Additionally, if at a specific point on a single reaction zone the thickness is locally four times thicker than the laminar value and its length to thickness ratio is less than four, it is identified as being locally distributed at that point. In contrast, if this ratio exceeds four or the zone is not locally four times thicker than the laminar value it is considered to be thickened at that point. A reaction zone is defined to be partially distributed when more than $25 \%$ of the reaction surface consists of locally distributed reaction zones. The reaction zone is defined to be "broken" when its burning fraction drops below 0.75 .

The categorization of each case into its appropriate regime was based on the aforementioned definitions and the data shown in the figures above. A summary of this categorization is provided in Table 2 below. 


\begin{tabular}{lcc}
\hline & Preheat zone & Reaction zone \\
\hline Case 1: & thickened preheat zone & continuous, thickened reaction layers \\
Case 2: & "globally distributed" preheat zone & continuous, thickened, partially-distributed reactions \\
Case 3: & "globally distributed" preheat zone & continuous, thickened, partially-distributed reactions \\
Case 4: & "globally distributed" preheat zone & broken, thickened reaction layers \\
\hline
\end{tabular}

Table 2. Classification of the four cases studied in this paper.

\section{F. Tortuosity measurements}

The tortuosity, which quantifies the degree of "wrinkledness" of the flame front, can be calculated from the overlapped PLIF images. Tortuosity, $\Omega$, is defined as the perimeter of the contour through the center of the wrinkled

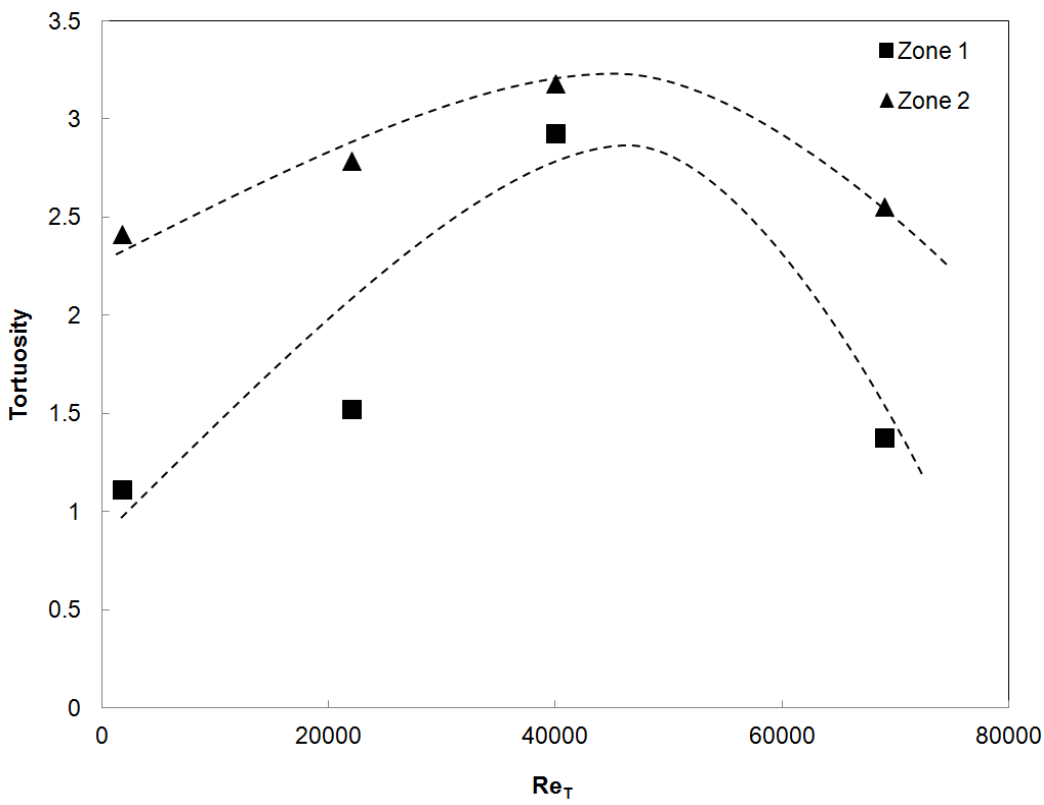

Figure 18. Tortuosity of the reaction zone as a function of turbulent Reynolds number. The flame becomes more wrinkled as turbulence increases until the flame front begins to break apart into smaller, less wrinkled units. reaction zone, $\mathrm{L}_{\mathrm{RZ}}$, divided by the distance between the two endpoints, $\Delta_{\text {end. }}$ An equation for tortuosity is provided in Eq. (9) below:

$$
\Omega=\frac{\mathrm{L}_{\mathrm{RZ}}}{\Delta_{\mathrm{end}}}
$$

A value of one would indicate a straight line and larger values indicate higher levels of wrinkling. Measured values of tortuosity are shown in Figure 18. Two general trends are observed. First, as HAB increases the flame becomes more wrinkled for all cases. Second as the turbulent Reynolds number increases, the flames initially experience more wrinkling. This continues until local extinctions occur and the flame relaxes to small pockets of less wrinkled reactions.

\section{Conclusions}

1. Four different non-reacting flow fields issuing from the Hi-Pilot burner were characterized using laser Doppler Velocimetry (LDV). The turbulence Reynolds number of these four cases spanned from 1,800 to 69,000, the turbulence intensity (i.e. $\mathrm{u}^{\prime} / \mathrm{S}_{\mathrm{L}}$ ) ranged from 6.8 to 185 , and the integral length scale varying between $17 \mathrm{~mm}$ and $28 \mathrm{~mm}$.

2. Preheat zone thicknesses, based on $\mathrm{CH}_{2} \mathrm{O}$ PLIF signals, were found to exceed six times the laminar value. Six of the eight conditions considered (zones 1 and 2 of cases $2-4$ ) possessed average preheat zone thicknesses above four times the laminar thickness, hence these cases were identified as having globally distributed preheat zones.

3. As the turbulence Reynolds number increases beyond 20,000, preheat zone thickness exhibit an asymptotic behavior. This is believed to occur because there is a finite amount of area within the conical region of reactants inside the flame brush, and for $\operatorname{Re}_{\mathrm{T}}>40,000$ the preheat zone becomes so large that it fills the entire central region of the flame. Therefore, the preheat zone cannot grow any larger for this geometry. 
4. Reaction zones were identified by taking the pixel-by-pixel product of the $\mathrm{OH}$ and $\mathrm{CH}_{2} \mathrm{O}$ PLIF images. Reaction zone thicknesses increase with increasing turbulence Reynolds number up to 30,000. Thereafter, the thickness of the reaction zone decreases with increasing turbulence Reynolds number.

5. Globally, all eight cases were found to have thickened reaction zones; that is, none of the cases possessed an average reaction zone thickness greater than four times the laminar value.

6. Four of the eight cases (zones 1 and 2 of case 2 and zone 2 of cases 3 and 4) are deemed to be partially distributed because, per our definition, more than $25 \%$ of their reaction surfaces are locally distributed. A reaction surface is considered to be locally distributed if its thickness is locally four times thicker than the laminar value and its length to thickness ratio is less than four.

7. The burning fraction $(B F)$ quantifies the amount of local extinction occurring in the flame. A near unity burning fraction corresponds to continuous reaction surfaces; while a $\mathrm{BF}<75 \%$ was defined as the boundary of broken reaction zones. $B F$ was found to decrease with turbulence Reynolds Number, indicating an increase in local extinction as the turbulence intensity increases. Four of the eight test cases were determined to have broken reaction zones.

8. Currently, there are not sufficient data to map out the regime boundaries. Nevertheless, the cases considered in this study were classified into their appropriate regimes.

9. The flames' tortuosity, which is a measure of flame wrinkling, was found to increase with increasing turbulent Reynolds number until local extinctions occurred which broke the flame into multiple unwrinkled segments.

10. All of the parameters, except for the burning fraction, were found to increase with height above burner. The burning fraction decreased with height above burner, which indicates an increase in the degree of local extinction as the stabilizing effects near the burner's surface are removed.

\section{Acknowledgements}

Support for this research was provided by AFOSR Grant FA9550-12-1- 0101 that was monitored by Dr. Chiping Li.

\section{References}

${ }^{1}$ I.G. Shepherd, R. K. Cheng, Combust. Flame 127 (2001) 2066-2075.

${ }^{2}$ A. Buschmann, F. Dinkelacker, T. Schafer, M. Schafer, J. Wolfrum, J.. Proc Combust. Inst. 26 (1996) 437-445.

${ }^{3}$ A. Soika, F. Dinkelacker, A. Leipertz, Proc. Combust. Inst . 27 (1998) 785-792.

${ }^{4}$ Y.-C. Chen, R. W. Bilger, Combust. Flame 131(2002) 400-435.

${ }^{5}$ J. F. Driscoll, Prog. Energy \& Combust. Sci. 34 (2008) 91-134.

${ }^{6}$ A. M. Steinberg, J. F. Driscoll, Combust. Flame 157 (2010) 1422-1435.

${ }^{7}$ A. M. Steinberg, J. F. Driscoll, Expts. in Fluids 47 (2009) 527-547.

${ }^{8}$ J. B. Bell, M.S. Day, J. F. Grcar, M.J. Lijewski, J. F. Driscoll, S. Filatyev, Proc. Combust. Inst. 31 (2007) 12991307.

${ }^{9}$ H. Kobayashi, T. Kawahata, K. Seyama, T. Fujimari, J.S. Kim, Proc. Combust. Inst. 29 (2002) 1793-1800.

${ }^{10}$ R. Sankaran, E.R. Hawkes, J.H. Chen, JH., Proc, Combust, Inst, 31(2006)1291-1298.

${ }^{11}$ F.T.C. Yuen, O. Gulder, Proc. Combust. Inst. 34 (2013) 1393-1400.

${ }^{12}$ M.J. Dunn, A. R. Masri, R. W. Bilger, R.S. Barlow, G.S. Wang, Proc. Combust. Inst. 32 (2009) 1779-1786.

${ }^{13}$ M.J. Dunn, A. R. Masri, R. W. Bilger, R S. Barlow, Flow Turbulence Combust. 85 (2010) 621-648.

${ }^{14}$ Z. Bo, C. Brackmann, Z. Li, M. Alden, X. Bai, Combust. Inst. 35 (2014) (In Press).

${ }^{15}$ A. J. Aspden, M. S. Day, J. B. Bell, J. Fluid Mech. 680 (2011) 287-320.

${ }^{16}$ F. A. Williams, Combust. Flame 26 (1976) 269-276. Also see Turns, S., An Introduction to Combustion, McGraw Hill Pub., N.Y. 2000.

${ }^{17}$ R. Borghi, Prog. Energy Combust. Sci. 14 (4) (1988) 245-292.

${ }^{18}$ N. Peters, Turbulent Combustion, Cambridge U. Press, Cambridge UK, 2000.

${ }^{19}$ A. Marshall, P. Venkateswaran, D. Noble, J. Seitzman, T. Lieuwen, Expt. Fluids 51 (2011) 611-620. 
${ }^{20}$ B. Videto, D. Santavicca, Combust. Sci. Technol. 76 (1):159-164.

${ }^{21}$ T. Hedman, K. Cho, A. Satija, L. Groven, R. Lucht, S. Son, Experimental observation of the flame structure of a bimodal ammonium perchlorate composite propellant using 5 kHz PLIF, Combustion and Flame 159 (2012) 427437

${ }^{22}$ M. Richter, R. Collin, J. Nygren, M. Alden, L. Hildingsson, B. Johansson, Studies of the Combustion Process with Simultaneous Formaldehyde and OH PLIF in a Direct-Injected HCCI Engine, JSME International Journal, Series B, Vol 48, No. 4, 2005.

${ }^{23}$ B.O. Ayoola, R. Balachandran, J.H. Frank, E. Mastorakos, C.F. Kaminski, Combust. Flame 144 (2006) 1-16.

${ }^{24}$ A. Fayoux, K. Zahringer, O. Gicquel,.C. Rolond, Proc. Combust. Inst. 30 (2005) 251-257.

${ }^{25}$ H.N. Najm, P.H. Paul, C.J. Mueller, P.S. Wyckoff, Combust. Flame 113 (1998) 312-332.

${ }^{26}$ C.M. Vagelopoulos, J.H. Frank, Proc. Combust. Inst. 30 (2004) 241-249.

${ }^{27}$ S. Böckle, J. Kazenwadel, T. Kunzelmann, D.-I. Shin, C. Schulz, J. Wolfrum, Proc. Combust. Inst. 28 (2000) 279286.

${ }^{28}$ J. Kariuki, A. Dowlut, R. Yuan, R. Balachandran, Combust. Inst. 35 (2014) (In Press).

${ }^{29}$ Z. Li, B. Li, Z. Sun, X. Bai, M. Alden, Combustion and Flame 157 (2010) 1087-1096.

${ }^{30}$ Sumengen, B., "A Matlab toolbox implementing Level Set Methods," Vision Research Lab at UC Santa Barbara, California, October 2005. [http://barissumengen.com/level_set_methods/. Accessed 3/15/14.].

${ }^{31}$ Osher, S., Fedkiw, R., Level Set Methods and Dynamic Implicit Surfaces, Springer, New York, 2003.

${ }^{32}$ Marshall, A., Venkateswaran, P., Noble, D., Seitzman, J., Lieuwen, T., Development and characterization of a variable turbulence generation system. Exp. Fluids 51:611-620

${ }^{33}$ Mayo, W.T. Jr., A discussion of limitations and extensions of power spectrum estimation with burst-counter LDV systems. International workshop on laser velocimetry, West Lafayette, Indiana, Purdue University, pp 90-101, 1974.

${ }^{34}$ Tummers, M.J., Passchier, D.M. Spectral estimation using a variable window and the slotting technique with local normalization. Meas. Sci. Technol. 7:1541-1546, 1996.

${ }^{35} \mathrm{H}$. Tennekes, and J. Lumley, A first course in turbulence. The MIT press, Cambridge, 1972.

${ }^{36}$ M.J. Dunn, A. R. Masri, R. W. Bilger, Combust. Flame 151 (2007) 46-60.

${ }^{37}$ Mallard, E., and LeChatelier, H.L., Ann. Mines (1883) 379-568.

${ }^{38}$ Kuo, K.K., Principles of Combustion, $2^{\text {nd }}$ ed., Wiley \& Sons, Inc., New Jersey, 2005. 